\title{
Blood vessel architectural features and their effects on thermal phenomena
}

John Pearce, Sharon Thomsen

John A. Pearce, Sharon L. Thomsen M.D., "Blood vessel architectural features and their effects on thermal phenomena," Proc. SPIE 10297, Matching the Energy Source to the Clinical Need: A Critical Review, 1029706 (24 January 2000); doi: 10.1117/12.375226

SPIE. Event: Digital Optical Computing, 1990, Los Angeles, United States 


\title{
Blood vessel architectural features and their effect on thermal phenomena
}

\author{
John A. Pearce and Sharon Thomsen \\ Biomedical Engineering Program, The University of Texas at Austin
}

\begin{abstract}
Blood vessels are anatomically and mechanically complex tissue structures. The particular architecture of arteries, veins and capillaries affects their response in therapeutic heating applications. This work summarizes the signal anatomic features of blood vessels for engineers and scientists, introduces the primary underlying physical principles which describe their function and response to external heating for clinicians, and provides a few representative examples of heating applications. It is by no means complete such a work would be at least two orders of magnitude longer - but, we hope, provides an adequate survey of the pertinent literature so that the interested can locate more substantial treatments of the subject.
\end{abstract}

Keywords: Blood vessels, quantitative histology, anatomical features, thermal surgery

\section{VASCULAR ANATOMY AND HISTOLOGY}

Blood vessels are hollow round tubes functioning as conduits for blood flow. Blood, a tissue composed of fluid (plasma) and the red (erythrocytes) and white (inflammatory) cells, is a major player in transport and transfer of heat, gases, nutrients and metabolic wastes in living systems. The circulatory system is designed for heat and mass transfer.

The basic structural anatomy of blood vessel walls is constant but the relative amounts of each component vary considerably among the different vessels to satisfy different design criteria and constraints. The blood circulation begins at the heart that pumps blood into the systemic vascular system via the aorta (about $1 \mathrm{~cm}$ in diameter) and the pulmonary vascular system via the pulmonary arteries (about 6 to $7 \mathrm{~mm}$ in diameter). The arteries become smaller in diameter and their function changes from a major conduit to smaller delivery pipelines feeding blood to the various organs and tissues, the medium sized arteries. Once these feeder arteries enter into the organs they branch into smaller and smaller arteries to form very small vessels, the arterioles. The arterioles branch further and, ultimately, form the smallest blood vessels, the capillaries $(5-10 \mu \mathrm{m}$ in diameter) through which gases, nutrients and waste materials are exchanged. The blood flow drains from the capillaries into venules that eventually empty into larger and larger veins to connect with the great veins, the superior and inferior vena cavae and the pulmonary veins. Veins in the lower extremities have valve leaflets approximately at $10 \mathrm{~cm}$ intervals to prevent back flow under hydrostatic loading and a tunica media as thick as arteries for the same reason. Venous flow in the extremities is driven by muscular contractions. Venous flow in the head and trunk is driven by expansion of the thorax during inspiration. The large veins $(1-3 \mathrm{~cm}$ in diameter) empty into the heart providing continuity in the flow system.

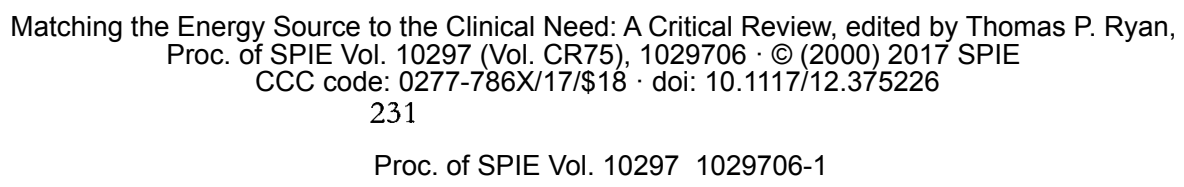


Histologic studies of vessels from different animals reveal significant species-dependent differences in the spatial distribution of the vessel constituents (vascular architecture) of analogous vessels; and significant architectural differences among different blood vessels in the same species. In other words, the physical and anatomic properties of one blood vessel cannot be applied to all other blood vessels, though there are global similarities.

\subsection{Tissue Constituents}

The basic wall structure of all blood vessels, except capillaries, is three-layered consisting of 1) the intima, the inner layer that lines the vascular lumen, 2) the media, the muscular/connective tissue middle layer and 3) the adventitia, the connective tissue outer layer. The intima is formed of the endothelium, the lining epithelium that forms the luminal surface (about 3 to $5 \mu \mathrm{m}$ thick), and the underlying myointimal tissue that supports the endothelium. The myointimal layer measures less than $5 \mu \mathrm{m}$ thick in most normal blood vessels and is formed of myointimal cells intermixed with a felt-work of small collagen fibers. The intima of arteries and veins is essentially the same; but the intima of capillaries consists of endothelium only.

The media is the most important wall component that controls blood flow and blood vessel conformation. To accomplish these functions, the media consists of variable amounts of contractile smooth muscle cells supported by a fibrillar collagenous scaffolding sandwiched between elastin fibers or plates. The arterial media can vary from 1-2 mm (aorta) to $10-15 \mu \mathrm{m}$ (precapillary arterioles) thick and contains variable ratios of muscle cells, elastin and collagen. The adventitia is the outer most mural layer and is formed of two sublayers. The inner sublayer is a dense, tightly-packed feltwork of collagen and elastin fibers. This layer is tightly adherent to the media and is difficult to dissect away from the vessel. The outer layer is a looser, network of thick collagen fibers that gradually blends with the surrounding tissues. This outer layer can be removed partially by blunt dissection. The adventitia is thicker in arteries than veins and, in general, is thicker relative to the media in larger vessels than in smaller ones. Most of the great arteries also have a network of smaller blood vessels in the adventitia, called the vasa vasorum, whose purpose is to perfuse the vessel tissues $1,2,3,4,5$.

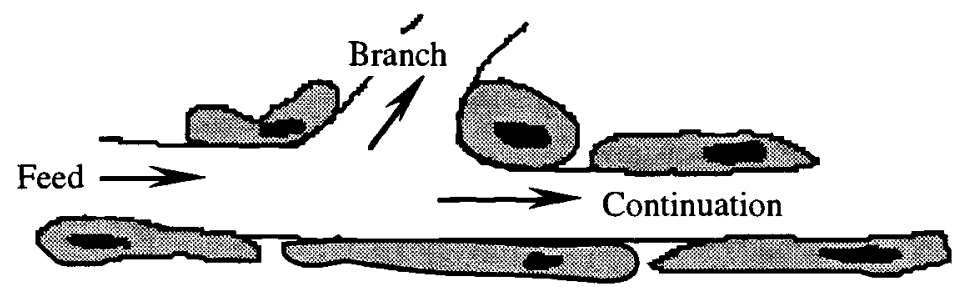

Figure 1. Sketch of representative endothelial cell morphology as typically seen around a branch in an arteriole ${ }^{6}$.

\subsubsection{Endothelium}

Endothelial cells are squamous epithelium specialized for lining the blood vessel. The endothelium is one cell layer thick $(1-3 \mu \mathrm{m})$ and forms an essentially continuous membrane. All vessels have an endothelial layer, and in capillaries the endothelium comprises the entire vessel wall. Endothelial cells communicate with each other through gap junctions to reform and remodel the vessel walls in response to wall shear stresses; 
key cells act as shear stress gradient sensors. The cells assume shapes appropriate to local gradients in wall shear, and have particularly interesting morphologies around bifurcations; especially in small arteriole branches where the cells range from 80 to 100 $\mu \mathrm{m}$ long and from quite flat to nearly cuboidal ${ }^{6}$, as depicted in Figure 1 .

\subsubsection{Smooth Muscle}

Vascular smooth muscle cells are the contractile elements that control blood flow and blood pressure gradients by contraction (vasoconstriction) or relaxation (vasodilatation) in response to a plethora of physiologic stimuli and feed-back signals through the nervous system, hormonal and other biochemical signal pathways. Therefore, smooth muscle is the more prominent vessel wall constituent in those arteries and sometimes the veins that control perfusion of a region, organ or tissue. These medium sized arteries are called "muscular" arteries in distinction to the elastin-rich larger "elastic" arteries, such as the aorta, carotid and femoral arteries. Local tissue perfusion pressures are generally governed by the vasodilatation and vasoconstriction of the arterioles; smooth muscle is generally wrapped circumferentially around the outside of an arteriole at strategic locations rather than located diffusely within the vessel wall, as in large vessels. Vascular smooth muscle maintains the mural "tone" of arteries and veins to provide constant perfusion pressure gradients. The vascular smooth muscles are harnessed by collagen scaffolding, elastin plates and fibers to transmit the work of each cell to the vascular wall. The muscle cells are typically oriented circumferentially or spirally relative to the axis of the vessel.

\subsubsection{Collagen}

Collagen includes a group of fibrillar proteins, or web-like proteins, that form the major constituent of connective tissue. Examples are: 1) the tendons and fibrous sheaths (fascia) of muscles, 2) skin dermis and 3) the meninges, tissue sheets that cover the brain and spinal cord. The collagens of non-diseased blood vessels form a delicate, fibrillar scaffolding that supports the vascular smooth muscles and interacts with the elastin in the vascular media. The adventitial collagens form thick fibers arranged in a felt-work that encompasses the adventitial elastin then extends to blend with the surrounding tissues. The collagens and elastin are produced by myointimal cells, fibroblasts and myofibroblasts, cells that reside in the vessel wall.

Collagen chemistry is much studied - to date at least fourteen types of collagen molecules have been described. A very effective collection of information on the collagens is the multiple volume series edited by Nimmi, the first volume of which describes collagen biochemistry?

\subsubsection{Elastin}

Elastin is a fibrillar protein that forms dense fibers and flat plates in the media and adventitia of arteries and veins. Elastin's elastic properties allow arteries and their components to respond to the relentless pounding of pulsatile blood flow in the large arteries and to store the potential energy required to maintain blood flow during diastole. Also, elastin interacts with the more rigid, strong medial and adventitial collagen to maintain the structural integrity of the blood vessels. An almost continuous, distinct elastin membrane, the internal elastic lamina, separates the intima from the media in all systemic and pulmonary arteries. A distinct internal elastic lamina is not present in capillaries and veins. Most elastin is present in the media and the adventitia of both arteries and veins. Arterial medial elastin plates and fibers tend to be parallel to the long 
axes of the vessel and form more or less regular layers. The medial elastin fibers in veins have a looser, less layered distribution than those of arteries. The elastin fibers of the adventitia form a feltwork layer just adjacent to the media in both arteries and veins. The density, volume fraction and distribution of elastin fibers varies considerably among different blood vessels in the same animal and for the same vessel in different species, and also from point to point in the same vessel. For example, the media of the human aorta and its major branches contain more elastin plates and fibers than the medium-sized arteries entering the organs such as the kidney, heart and gut. On the other hand, the adventitia of medium-sized veins and arteries of pigs contain more elastin than the same vessels in mongrel dogs: the same human vessels have less adventitial elastin than either animal.

\subsection{Small Vessels}

Small diameter capillaries ( 5 to $10 \mu \mathrm{m}$ diameter) are the final sites of mass transfer in the body. The three basic types of capillaries are: 1) continuous endothelium with micropinocytosis, 2) fenestrated (i.e. perforated) endothelium - some fenestrae are open while others are closed by diaphragms ${ }^{5}$, and 3) discontinuous endothelium and/or sinusoids. Non-fenestrated continuous capillaries have endothelial cells held tightly together by gap junctions and desmosomes. Fenestrated capillary endothelial cells have 60 to $100 \mathrm{~nm}$ pores, and the variety with diaphragms occurs in tissues requiring rapid fluid exchange (gastro-intestinal mucosa, kidney peritubular plexus cells etc.) ${ }^{5}$. Larger open fenestrations are typical of capillaries in the carotid and aortic bodies 5 . The normal pressure difference between the arterial and venous ends of the capillary is around 10 to 20 torr (mmHg). Junctional complexes between the endothelial cells occur at intervals ${ }^{5}$ in continuous endothelium and permit passive diffusion of fluids, osmotic proteins and nutrients into the extracellular space of the surrounding tissue near the arterial end and collection of fluids, osmotic proteins and waste products near the venous end.

Venules collect blood from capillaries and are of larger diameter but otherwise nearly indistinguishable. Their walls are composed similarly to capillaries consisting of endothelium essentially without a muscular shroud.

Arterioles have endothelial cells surrounded by basement membrane and a spiraling monolayer of smooth muscle cells at varying intervals and locations ${ }^{5}$. One smooth muscle cell may spiral several times around an arteriole. Contraction narrows the arteriole diameter to control flow. The adventitia of arterioles contains fibroblasts, collagen fibers and sparsely distributed muscle cells. A few delicate longitudinal elastin fibers are distributed just inside the endothelium and its basement membrane (the tunica intima of an arteriole).

\subsection{Image Orientation and Histologic Stain Characteristics:}

1) Weigert-vanGieson elastin stain colors elastin fibers black, collagen red and smooth muscle a light yellow-tan. In the black and white images these correspond to black, dark gray and light gray, respectively.

2) Mallory's trichrome stain colors elastin pink, collagen bright blue and smooth muscle pale yellow. In the black and white images these correspond to very light gray, dark gray and light gray, respectively. 
3) hematoxylin and eosin stains most cellular components a light salmon color and the cell nuclei purple. In the black and white images these correspond to very light gray and dark gray, respectively.

All higher power images have the intimal surface on top and the adventitia on bottom. Collagen native and form birefringence yields bright areas on an otherwise dark field under transmission polarizing microscopy (TPM). Birefringence images in this paper are usually taken from H\&E stained sections.

\subsection{Middle Sized Vessels}

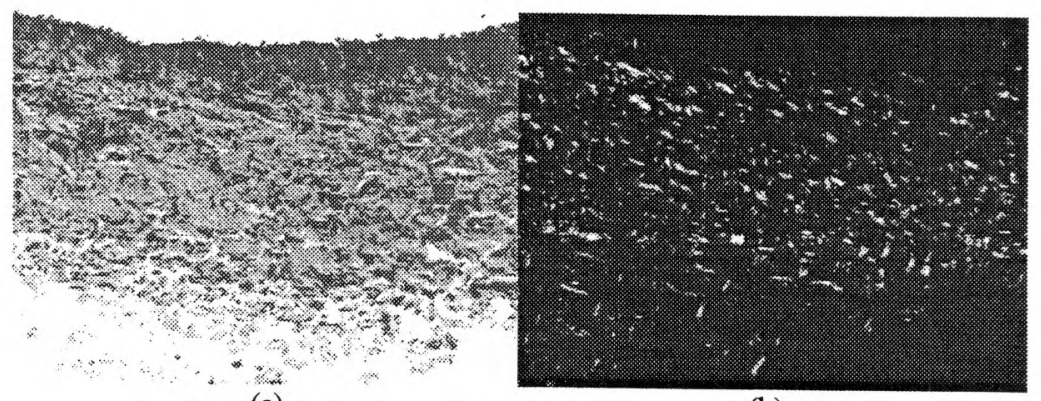

(a)

(b)

Figure 2. The renal vein in the pig at original magnification 40X, (a) hematoxylin and eosin stain $(\mathrm{H} \& \mathrm{E})$ reveals smooth muscle nuclei (darker spots) distributed throughout the vessel wall and the transmission polarizing microscopy view (TPM), (b) shows the relatively uniform collagen distribution (the bright field).

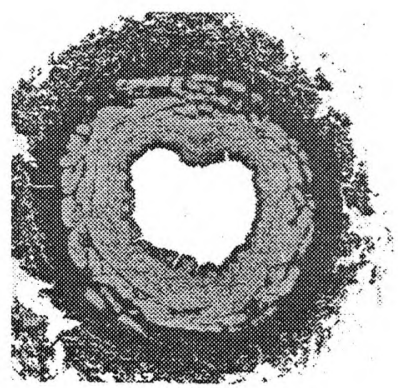

(a)

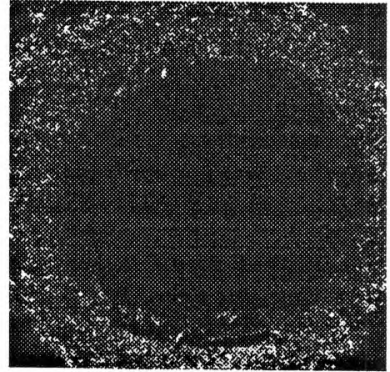

(b)

Figure 3. The renal artery in the pig at original magnification $6.25 \mathrm{X}$, (a) Elastin stain reveals smooth muscle packed media nearly devoid of elastin with elastin-rich adventitia as a dense feltwork. b) the transmission polarizing microscopy view (TPM) shows collagen loosely distributed in the outer adventitia only.

Medium sized and smaller arteries and veins tend to be paired or arranged in groups called "vascular bundles", frequently grouped with a major nerve, as well. The arteries have smaller outer and luminal diameters and thicker, more rigid walls than those of their companion veins. Frequently, veins are more easily recognized than arteries by their larger size and the red blood visible through their thin walls. The artery and nerve in the bundle often have similar size and appearance at first glance. 


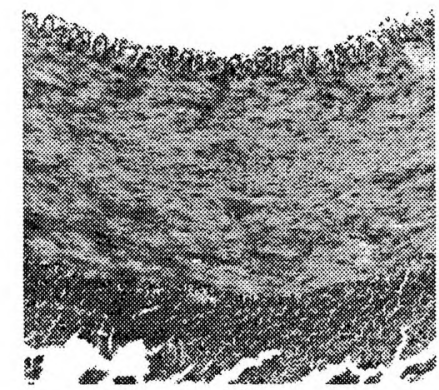

(a)

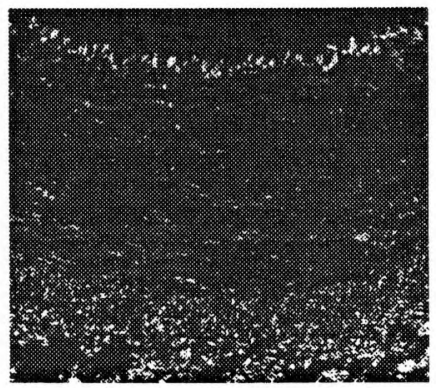

(b)

Figure 4. The splenic artery in the pig at original magnification 40X. a) hematoxylin and eosin stain (H\&E) reveals smooth muscle and myointimal cell nuclei (darker spots) distributed throughout the vessel wall. b) transmission polarizing microscopy (TPM) shows a more uniform collagen distribution (bright field) than the renal artery.

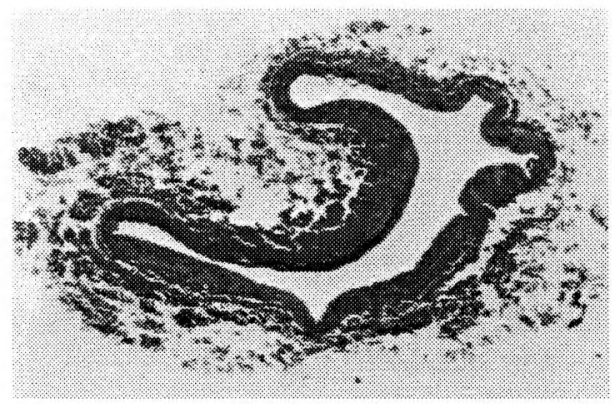

(a)

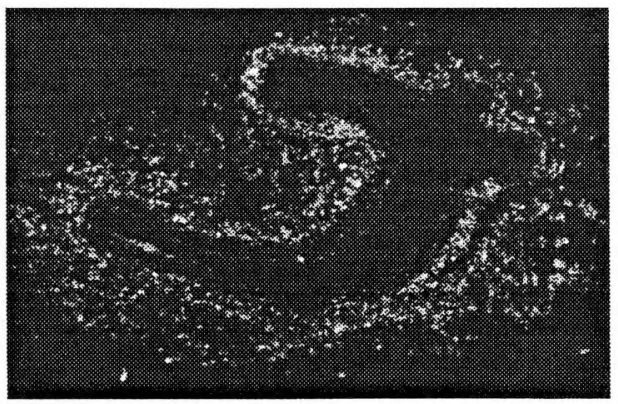

(b)

Figure 5. The splenic vein in the pig at an original magnification of $6.25 \mathrm{X}$ : a) H\&E stain; b) TPM delineates the adventitial collagen.

\subsection{Large Vessels}

The aorta has substantial structure devoted to storage of blood pulse energy in elastin bands and plates and ultimate strength in a surrounding collagen harness. In figure 7 the aorta in the pig may be seen to be a little thinner in cross-section than the canine aorta of figure 6 (note magnification $31 \mathrm{X}$ compared to $25 \mathrm{X}$ for the canine aorta). Aorta biomechanics is an intricate problem combining both fluid mechanics forces and pressure stress forces which are not in phase.

Figure 8 illustrates the typical architecture of the canine femoral artery and vein and the pig femoral artery for comparison. The femoral arterial media is separated from the intima by a prominent lamina propria. The media consists mainly of smooth muscle cells supported by a collagen framework and spare, thin elastin plates in the dog and thick well organized plates in the pig. In the dog, the femoral arterial adventitia is composed of a thick elastin feltwork that is almost as thick as the media. The femoral vein has a thinner wall with no internal elastic lamina and ribbons of elastin interspersed with dense 
collagen fibers and smooth muscle cells. A TPM image (not shown) reveals very little collagen in the media and a dense feltwork of collagen in the adventitia for the pig femoral artery section.

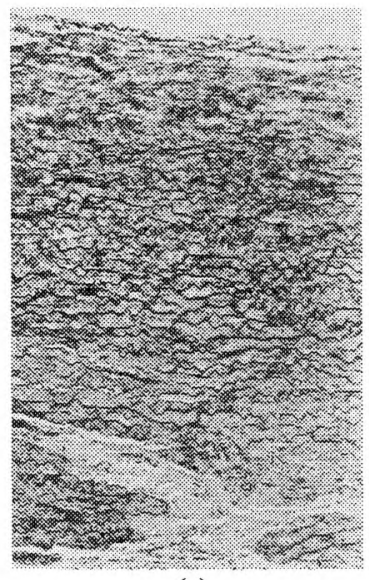

(a)

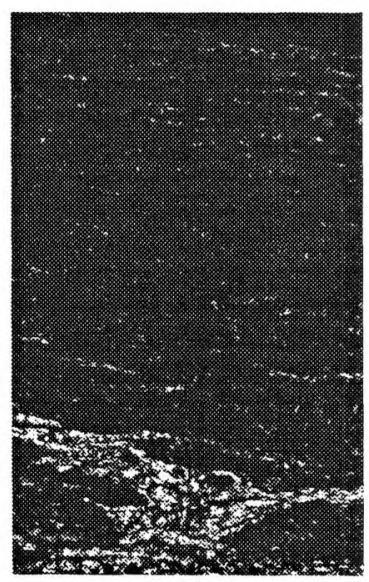

(b)

Figure 6. Canine aorta at an original magnification of $25 \mathrm{X}$. a) Hematoxylin and eosin (H\&E) shows elastin plates as medium gray with sparse smooth muscle nuclei (dark spots) at this location. b) Transmission polarizing microscopy (TPM) reveals sparse collagen in the media with a denser feltwork in the adventitia.

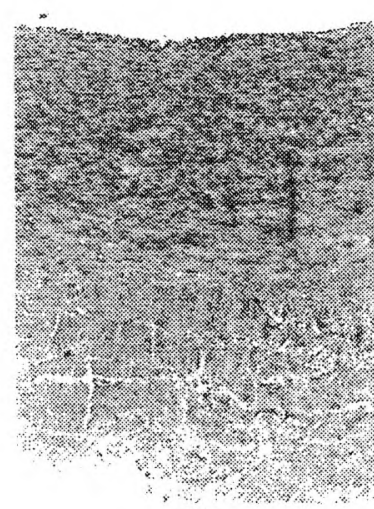

(a)

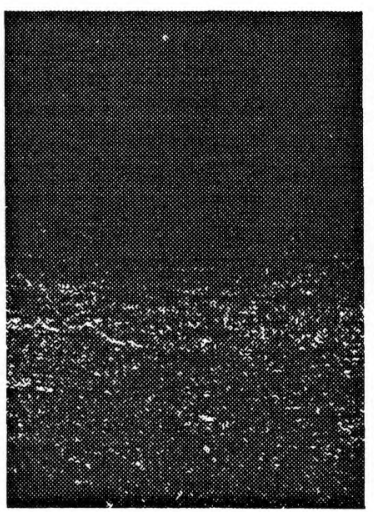

(b)

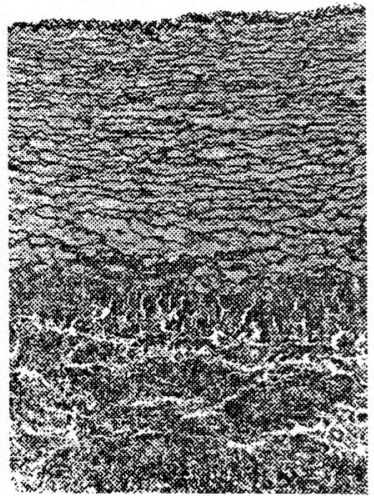

(c)

Figure 7. Porcine aorta sectarian at an original magnification of $31 X$. (a) Hematoxylin and eosin (H\&E) stain reveals smooth muscle nuclei (dark spots). (b) Transmission polarizing microscopy (TPM) of the same section shows a loose collagen feltwork in the adventitia. (c) Weigert-vanGieson elastin stain of an adjacent section illuminates the thin elastin plate arrangement.

Two sections of the canine carotid artery are shown in Figure 9. The specimen shown in Figure $9 \mathrm{a}$ was collected near the origin of the carotid artery at the aorta and the specimen in $9 \mathrm{~b}$ is from the middle of the common carotid. The proximal carotid artery has a thick media composed of prominent elastin plates connected by a collagenous scaffolding in 
which smooth muscle cells are found. The internal elastic lamina (luminal surface) is thin and mingles with the medial elastin. The adventitia (not shown) consists of a dense feltwork of collagen. On the other hand, the intimal surface of the middle carotid artery is separated from the media by a continuous (except for very small pores) elastic membrane, the internal elastic lamina. The media is composed of sheets of smooth muscle cells separated by irregular elastin plates and ribbons and by collagen. The proximal adventitia is a dense feltwork of elastin fibers that gradually intermixes with the collagen of the more peripheral adventitia.

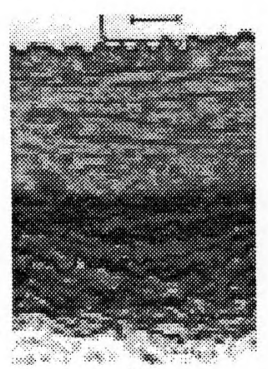

(a)

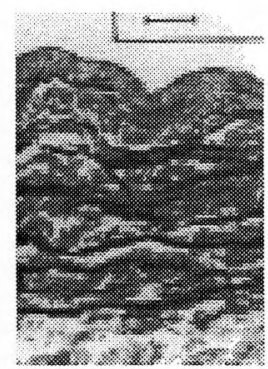

(b)

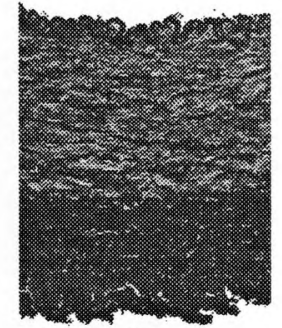

(c)

Figure 8. Canine Femoral Artery (a) and Femoral Vein (b). For comparison, the femoral artery in the pig at $40 \mathrm{X}$ original magnification . [Elastin Stain. Bar (a) $=99 \mu \mathrm{m}$ and $(b)=62 \mu \mathrm{m}]$. Note the difference in elastin distribution in the two species: the media has only a small amount of elastin in the dog and is a bit more elastin-rich and plate-like in the pig. The feltwork in the adventitia is more dense in the pig specimen, (c).

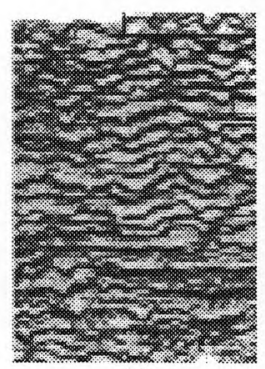

(a)

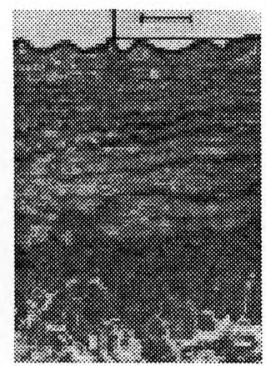

(b)

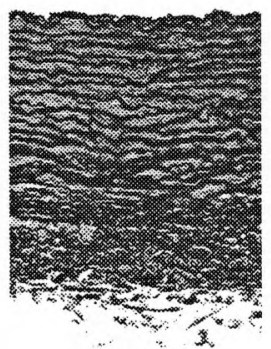

(c)

Figure 9. Proximal Carotid Artery (a) and Middle Carotid Artery (b) in the dog. For comparison, the subclavian artery in the pig at $40 \mathrm{X}$ original magnification (c) has elastin plates in the media and dense but more disorganized elastin sheets in the adventitia. The elastin is black, the collagen, medium gray, and vascular smooth muscle, light gray. [Elastin Stains. Bar $=62 \mu \mathrm{m}$ in both (a) and (b)] 


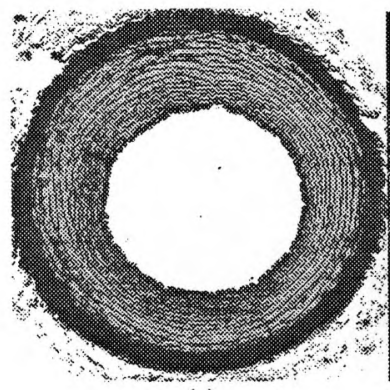

(a)

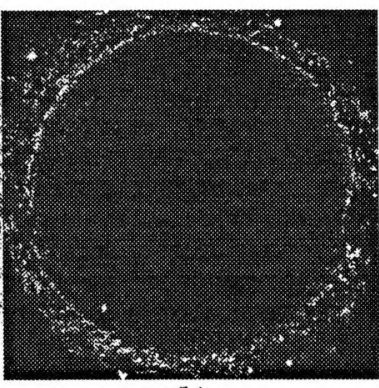

(b)

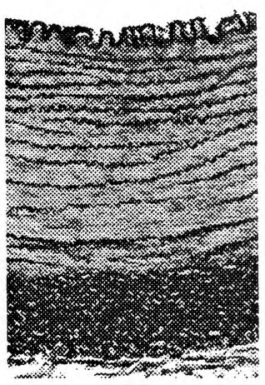

(c)

Figure 10. Carotid Artery in the pig elastin stain, (a) and TPM view, (b) at an original; magnification of $8 \mathrm{X}$. (c) is the same section at $40 \mathrm{X}$ original magnification. The media has elastin plates and dense but more disorganized elastin sheets in the adventitia.

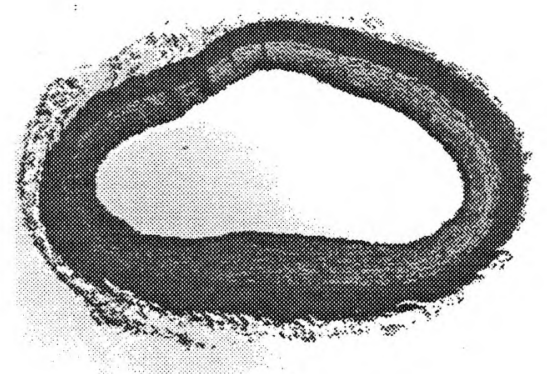

(a)

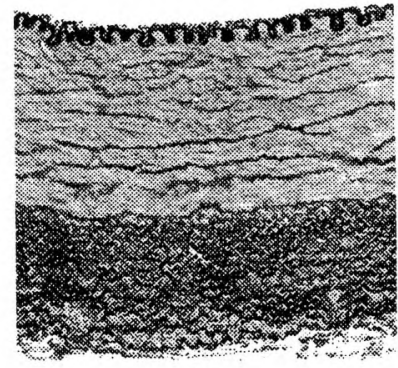

(b)

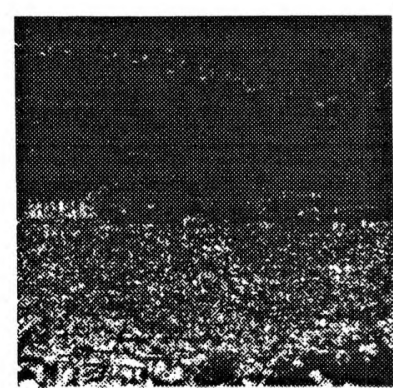

(c)

Figure 11. Iliac Artery in the pig elastin stain, (a), at an original magnification $6.25 \mathrm{X}$. b) the same section at an original magnification of $40 X$. (c) TPM view of the same section, also at $40 \mathrm{X}$. The media has elastin plates and dense and relatively organized elastin sheets in the adventitia.

The internal jugular vein in the pig (figures 12 and 13) illustrates the complimentary distribution of constituents. The H\&E section,(a) reveals muscle cell nuclei, the Transmission polarizing microscopy (TPM) section, (b), shows the collagen distribution and the elastin stain, (c), identifies the elastin distribution. Smooth muscle occurs in the dark gaps in the birefringence image (b). Elastin is primarily distributed throughout the adventitia and in specific plates in the media. In the dog the internal jugular vein is also 
elastinized, but with a sparse distribution of thin plates, some of which may just be seen in the H\&E stained section of figure 14.

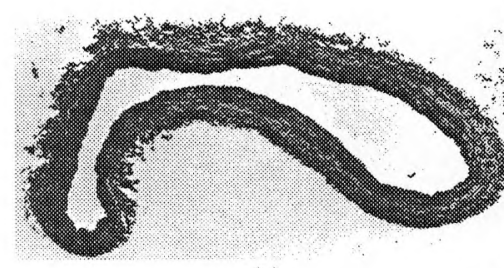

(a)

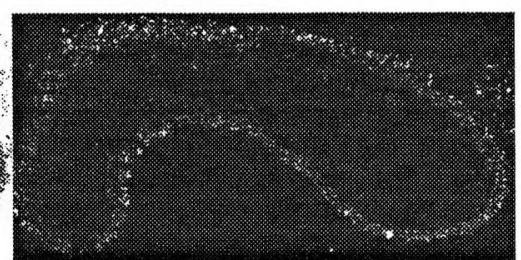

(b)

Figure 12. The internal jugular vein in the pig at original magnification $8 \mathrm{X}$. (a) Elastin section shows elastin bands in the media and outer adventitia. (b) Transmission polarizing microscopy shows collagen distribution (bright field) primarily in the adventitia.

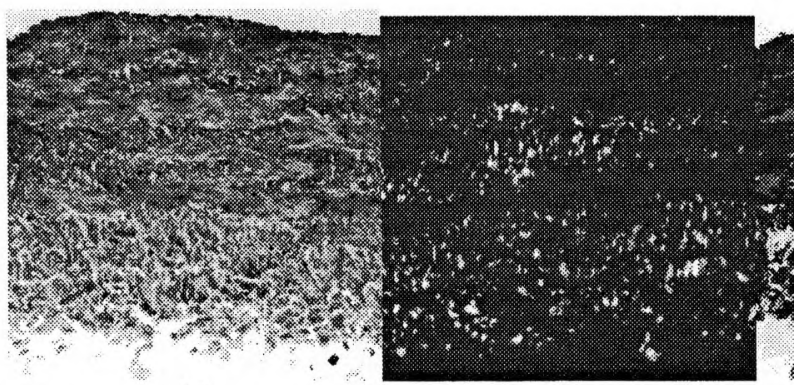

(a) (b)

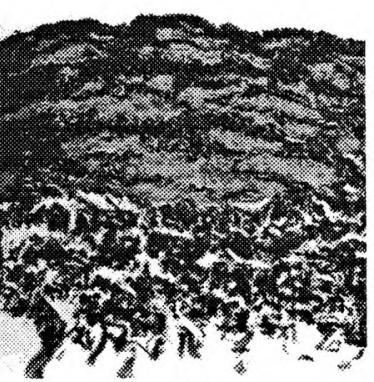

(c)

Figure 13. The internal jugular vein in the pig at original magnification $40 \mathrm{X}$. (a) $\mathrm{H} \& \mathrm{E}$ section. (b) Transmission polarizing microscopy shows collagen distribution (bright field). (c) Weigert vanGieson elastin stain gives a better picture of the elastin bands at this magnification.

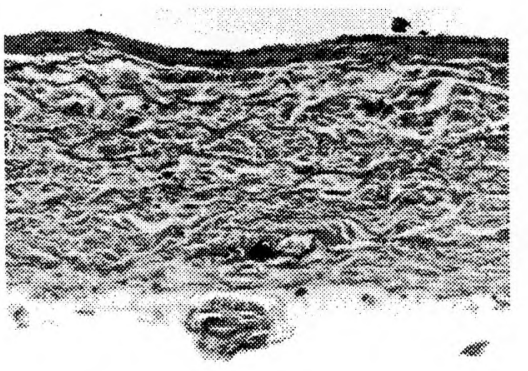

(a)

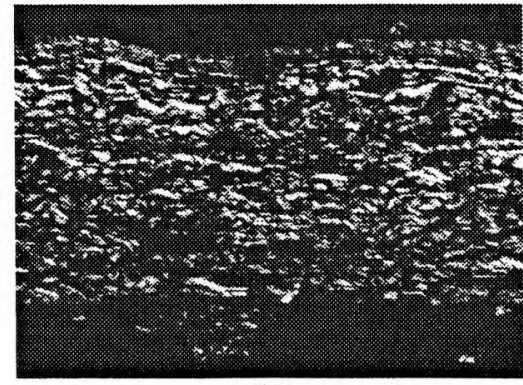

(b)

Figure 14. The internal jugular vein in the dog at original magnification $40 \mathrm{X}$ under $\mathrm{H} \& \mathrm{E}$ staining. a) The section is slightly thinner than in the pig. b) TPM view of the same section (also at $40 \mathrm{X}$ ) shows a surprisingly uniform distribution of collagen in sharp contrast to the pig internal jugular vein. 


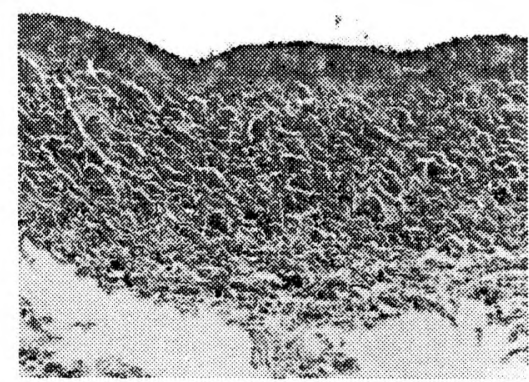

(a)

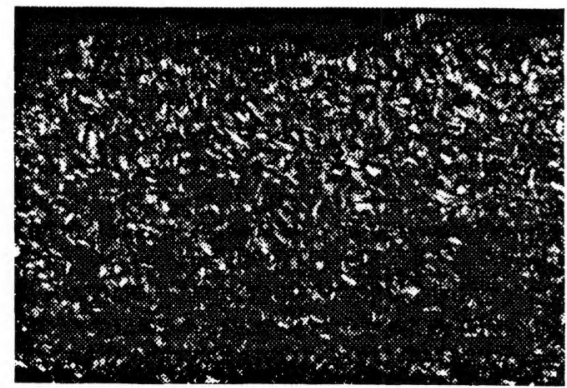

(b)

Figure 15. The femoral vein in the dog at original magnification $25 \mathrm{X} \mathrm{H} \& \mathrm{E}$ stain. a) is slightly thinner than in the pig. (b) TPM view of the same section (also at 25X) shows a surprisingly uniform distribution of collagen very similar to the internal jugular vein of figure 14 .

\begin{tabular}{ccc} 
Vessel & Media Thickness (mm) & Adventitia Thickness (mm) \\
\hline \hline Aorta & $0.471(0.035)$ & $0.229(0.068)$ \\
Subclavian A. (thick media) & $0.430(0.032)$ & $0.045(0.02)$ \\
Subclavian A. (thin media) & $0.257(0.016)$ & $0.190(0.037)$ \\
Carotid A. (elastic region) & $0.402(0.015)$ & $0.047(0.01)$ \\
Carotid A. (musc. region) & $0.0461(0.022)$ & $0.146(0.01)$ \\
Iliac A. & $0.258(0.04)$ & $0.185(0.015)$ \\
Femoral A. & $0.274(0.06)$ & $0.139(0.025)$ \\
Mesenteric A. & $0.186(0.017)$ & $0.095(0.028)$ \\
Splenic A. & $0.255(0.018)$ & $0.105(0.02)$ \\
Renal A. & $0.36(0.05)$ & $0.18(0.05)$ \\
Int. Jugular V. & $0.095(0.075)$ & $0.145(0.03)$
\end{tabular}

Table 1. Dimensional data for great vessels in the pig, average and (standard deviation).

\begin{tabular}{ccc} 
Vessel & Media Elastin (\%) & Adventitia Elastin (\%) \\
\hline \hline Aorta & $17.6(2.0)$ & $9.4(2.0)$ \\
Subclavian A. (thick media) & $52.3(2.7)$ & 26 to 54 \\
Subclavian A. (thin media) & $44.1(3.2)$ & $37.1(10.8)$ \\
Carotid A. (elastic region) & $56.4(1.2)$ & $21.8(1.7)$ \\
Carotid A. (musc. region) & $16.4(1.2)$ & $67.2(2.2)$ \\
Femoral A. & $8.4(2.1)$ & $80.0(5.1)$ \\
Femoral A. & $22.6(3.4)$ & $83.8(3.2)$ \\
Mesenteric A. & $11.5(1.5)$ & $61.2(7.7)$ \\
Renal A. & $7.5(0.1)$ & $47.3(8.7)$
\end{tabular}

Table 2. Relative elastin content for great arteries in the pig, average and (standard deviation). 


\begin{tabular}{ccc} 
Vessel & Media Elastin (\%) & Adventitia Elastin (\%) \\
\hline \hline Aorta (distal) & $21.4(2.1)$ & $16.4(5.4)$ \\
Aorta (proximal) & $19.9(5.5)$ & $23.0(11.1)$ \\
Carotid A. & 9.2 to $11.4(2.2$ to 3.2$)$ & 12.4 to $15.3(2.9$ to 3.0$)$ \\
Femoral A. & 1.0 to $3.0(0.4$ to 1.7$)$ & 37.4 to $47.8(2.7$ to 4.3$)$ \\
Femoral V.* & 1.2 to $2.8(0.4$ to 1.2$)$ & 13.4 to $16.0(1.9$ to 2.9$)$ \\
Common Iliac A. & 1.6 to $2.2(0.4$ to 0.5$)$ & 30.8 to $36.0(3.2$ to 4.2$)$ \\
Renal A. & 2.0 to $3.0(0.0)$ & 29.6 to $32.0(3.3$ to 8.3$)$
\end{tabular}

Table 3. Relative elastin content for great vessels in the dog, average and (standard deviation); ranges are given when several samples from different animals were analyzed.

\section{MECHANICAL PHENOMENA IN VESSELS}

Interplay among the fluid mechanical and vessel structural forces is a dominant feature of vessel design, and thus is a determining phenomenon for the vessel architecture. The delicate and subtle differences in vascular architecture exist to satisfy required performance criteria at different locations in the circulation and are no accident. Even though the basic mechanical phenomena play little role in therapeutic heating per se, their effect on the architecture certainly is of singular importance, and so it is worthwhile to review them to establish perspective. Beyond that, the thermodynamic and heat transfer characteristics are important in all therapeutic heating applications, and a review is included here, as well.

\subsection{Fluid Mechanics}

Blood flow has been a subject of considerable investigation from the early measurements of Harvey [in the 1600 's], to flow studies by Hagen ${ }^{8}$ and Poiseuille ${ }^{9}$, to a large body of recent work summarized effectively in $10,11,15$.

The continuity equation (conservation of mass) can be used to estimate average velocities from flowrates:

$$
\mathrm{Q}=\mathbf{u} \mathrm{A}
$$

where: $Q=$ the volume flow rate of blood $\left(\mathrm{m}^{3} / \mathrm{s}\right), \mathrm{u}=$ the speed $(\mathrm{m} / \mathrm{s})$ and $A$ is the crosssectional area of the vessel $\left(\mathrm{m}^{2}\right)$. A flow of $4 \mathrm{lpm}\left(66.7 \mathrm{~cm}^{3} / \mathrm{s}\right)$ in the descending aorta, about $1 \mathrm{~cm}$ in diameter $\left(\right.$ area $=0.785 \mathrm{~cm}^{2}$ ), has an average speed of $84.9 \mathrm{~cm} / \mathrm{s}$. The typical mass flow rate for normal cardiac output in the descending aorta, as in the above example, would be about $70 \mathrm{~g} / \mathrm{s}$.

The velocity is not uniform over the cross-section of the vessel: it is maximum at the center and zero at the wall, the so-called "zero slip" condition, due to affinity between blood plasma and the intimal surface. Thus, a velocity gradient always exists at any surface including vessels. A shear stress (force) is exerted on the wall given by:

$$
\tau=\mu \frac{\mathrm{du}}{\mathrm{dx}}
$$


where: $\tau$ is the shear stress $\left(\mathrm{N} / \mathrm{m}^{2}\right), \mu$ is the viscosity $\left(\mathrm{N}-\mathrm{s} / \mathrm{m}^{2}\right)$ and $\mathrm{x}$ is the direction normal to the vessel surface $(m)$. The surface velocity gradient, du/dx at $x=0$, is the shear rate The shear force vector acts along the direction of the vessel wall. The zero slip condition is not provable by molecular theory, but there is no experiment which indicates that the zero slip assumption is invalid ${ }^{11}$.

Blood is nearly a Newtonian fluid in large and medium sized vessels at ordinary shear rates. However, the non-Newtonian and multiphase nature of blood, where the semi-solid cells are suspended in plasma, are often important determinants of its behavior at high shear, especially in vessels smaller than $0.1 \mathrm{~mm}$ in diameter. In those vessels, and at locations of high shear rates in larger vessels, the viscosity of blood depends on the shear, and thus it is non-Newtonian. Additionally, the pulsatile nature of blood flow adds significant complication to its description by standard fluid mechanics means.

The characteristics of fluid flow fields change dramatically when viscous forces (equation 2) are more important than momentum forces, flow due to a pressure gradient. The primary parameter used to characterize the flow state is the non-dimensional Reynolds number, the ratio of momentum forces to viscous forces ${ }^{16}$ :

$$
\operatorname{Re}=\frac{\rho \mathrm{ud}}{\mu}
$$

where: $\rho=$ the density, $u=$ the average velocity and $d=$ vessel diameter. Matching the units in this relation requires some care. Reynolds numbers in excess of the "critical" value, about 2300 in cylindrical tubes, indicate that turbulent flow is likely. Low Reynolds numbers indicate that laminar flow dominates. In laminar flow the differential control volumes of fluid move in stream tubes parallel to the vessel walls and the velocity profile is parabolic across the vessel diameter and satisfies the "zero slip" condition at the wall. A thorough treatment of boundary layer theory may be found in the classical text by Schlicting ${ }^{17}$.

The time-average Reynolds numbers encountered in vessels are all below the turbulent transition range, about 1000 to 3000 in cylindrical tubes. In human aorta the average Reynolds number is in the range of 150 to $300^{12}$, but during a pulse the peak Reynolds number may exceed 500. As an example, if we take the simplified estimates from the above calculation for the aorta, $u=84.9 \mathrm{~cm} / \mathrm{s}, \mathrm{d}=1 \mathrm{~cm}$ with an estimated viscosity for blood at low shear of $3 \mathrm{mN}-\mathrm{s} / \mathrm{m}^{2}$ (estimated from Figure 10.8 of Caro et al ${ }^{11}$ ), the Reynolds number would be about 386 . The apparent viscosity of whole blood is very sensitive to shear rate, see Caro et $\mathrm{a}^{11}$, and so while the result is near the expected range there is a considerable band of uncertainty. In the right descending coronary artery $R e$ is the neighborhood of 200 to $300^{13}$ and in small arterioles it is around $0.01^{6}$.

Steady flow in small vessels is well described by the Hagen-Poiseuille result when the Reynolds number is around 1 or less:

$$
\Delta \mathrm{p}=128 \frac{\mu \mathrm{LQ}}{\pi \mathrm{d}^{4}}
$$

where: $\Delta p=$ the pressure difference between the inlet and outlet of the vessel $\left(\mathrm{N} / \mathrm{m}^{2}\right), \mathrm{L}$ is the vessel length $(\mathrm{m})$ and $\mathrm{d}$ its diameter $(\mathrm{m})$ and $\mathrm{Q}$ the flowrate $\left(\mathrm{m}^{3} / \mathrm{s}\right)$. 
In large vessels the multiphase nature of blood is significant near the wall where the shear rate is high. S.L. Soo ${ }^{14}$ has an excellent discussion of multiphase flow fields. Red blood cells near the wall spin and tumble ${ }^{11}$ in the velocity gradient (equation 2) and this leaves an RBC deficiency near the wall. Small vessels attached to the larger vessel receive blood with a significantly lower hematocrit than that of the free stream blood.

Flow in capillaries is decidedly different in nature. In a capillary vessel the red blood cell completely fills the vessel diameter as the cells squeeze through it. The flow has been described as "slug flow" and the RBCs are subjected to considerable mechanical deformation as they traverse the capillary.

The pulsatile nature of blood flow is important in all vessels. An unsteady flow, such as vessel flow, is generally described by the Womersley number, though it is probably not sinusoidal. The dimensionless Womersley number, $\alpha$, indicates the expected deviation from a Poiseuille (i.e. parabolic) velocity profile for a sinusoidally varying flow of angular frequency $\omega$ (radians/s):

$$
\alpha=\frac{\mathrm{d}}{2} \sqrt{\frac{\omega \rho}{\mu}}
$$

The flow is "quasi-steady" for values of $\alpha$ less than 1.0, the velocity profile is parabolic during the pulse and the magnitude of the flow rate is determined by the instantaneous pressure gradient (equation 4). At higher $\alpha$ the velocity profile is distorted since inertial forces dominate as the flow is accelerated and decelerated ${ }^{11}$.

In cases where the blood may be treated approximately as a Newtonian fluid the NavierStokes equations may be used to calculate the flow field - this nearly invariably requires a numerical solution except in the simplest of geometries. The Navier-Stokes equations include both momentum and viscous forces on a fluid volume and are more difficult to manage as a result. A finite control volume of fluid is subjected to both principal stresses (force per unit area, $\mathrm{N} / \mathrm{m}^{2}$ ) normal to the face, $\sigma_{\mathrm{jj}}$, due to pressure gradients, and shear stresses parallel to each face, $\tau_{\mathrm{ij}}$ due to viscous forces (see figure 16 ).

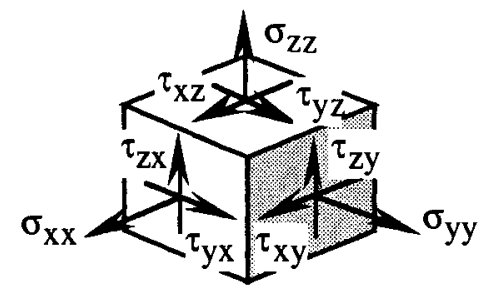

Figure 16: Fluid cube subjected to normal momentum stresses, $\sigma$, and shear stresses, $\tau$, as described by the Navier-Stokes equations.

There is one equation for each vector axis - Cartesian coordinates are used in this example and gravitational (body) forces have not been included: 


$$
\begin{gathered}
\rho\left(\frac{\partial u}{\partial t}+u \frac{\partial u}{\partial x}+v \frac{\partial u}{\partial y}+w \frac{\partial u}{\partial z}\right)=-\frac{\partial P}{\partial x}+\mu\left[\frac{\partial^{2} u}{\partial x^{2}}+\frac{\partial^{2} u}{\partial y^{2}}+\frac{\partial^{2} u}{\partial z^{2}}\right] \\
\rho\left(\frac{\partial v}{\partial t}+u \frac{\partial v}{\partial x}+v \frac{\partial v}{\partial y}+w \frac{\partial v}{\partial z}\right)=-\frac{\partial P}{\partial y}+\mu\left[\frac{\partial^{2} v}{\partial x^{2}}+\frac{\partial^{2} v}{\partial y^{2}}+\frac{\partial^{2} v}{\partial z^{2}}\right] \\
\rho\left(\frac{\partial w}{\partial t}+u \frac{\partial w}{\partial x}+v \frac{\partial w}{\partial y}+w \frac{\partial w}{\partial z}\right)=-\frac{\partial P}{\partial z}+\mu\left[\frac{\partial^{2} w}{\partial x^{2}}+\frac{\partial^{2} w}{\partial y^{2}}+\frac{\partial^{2} w}{\partial z^{2}}\right]
\end{gathered}
$$

or, put into vector form all three equations reduce to:

$$
\rho\left(\frac{\partial \mathbf{u}}{\partial \mathrm{t}}+\mathbf{u} \cdot \nabla \mathbf{u}\right)=-\nabla \mathrm{P}+\mu\left[\nabla^{2} \mathbf{u}\right]
$$

where: $u$ is the speed in the $x$-direction, $v$ in the $y$-direction, and $w$ in the $z$-direction, $u$ is the vector velocity field, and this formulation is for an incompressible fluid (blood).

\subsection{Structural Mechanics}

One of the most comprehensive and instructive recent treatments of arterial mechanics is that by Humphrey 19 . There are others, see for example 20, 21, 22, 24 which treat a variety of aspects of this intricate problem. These few paragraphs will only serve to very briefly summarize a few of the important points. The reader is commended to more serious literature on this subject.

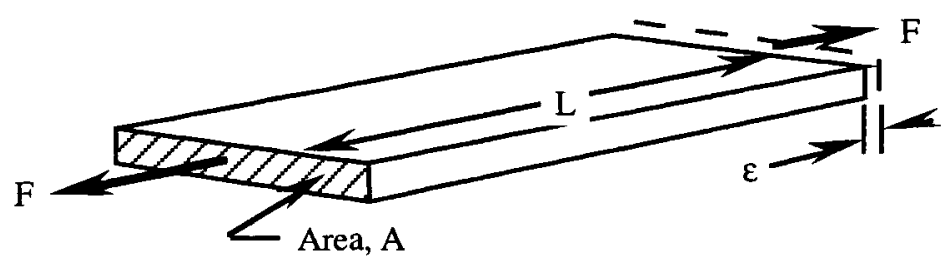

Figure 17. Applied force per unit area (stress, $\sigma_{\mathrm{m}}=\mathrm{F} / \mathrm{A}$ ) and resulting elongation (strain, $\varepsilon_{\mathrm{m}}$ $=\Delta \mathrm{L} / \mathrm{L})$.

Strain (i.e. stretch), $\varepsilon_{\mathrm{m}}(\mathrm{m} / \mathrm{m})$, in materials is the elongation or deformation in the direction of an applied stress (i.e. force per unit area), $\sigma_{\mathrm{m}}\left(\mathrm{N} / \mathrm{m}^{2}\right)$, please refer to figure 17. In metals the strain seldom exceeds about 0.002 , or $0.2 \% 19$. The modulus of elasticity, $E_{\mathrm{m}}$ (Young's modulus), relates principal stress and strain:

$$
\mathrm{E}_{\mathrm{m}}=\frac{\sigma_{\mathrm{m}}}{\varepsilon_{\mathrm{m}}}
$$


The shear modulus, $G_{m}$, relates torsional strain, $\gamma_{m}$, and applied shear stress, $\tau_{m}$ :

$$
\mathrm{G}_{\mathrm{m}}=\frac{\tau_{\mathrm{m}}}{\gamma_{\mathrm{m}}}
$$

In the general sense, a solid control volume is subject to at least as many stresses, both principal and shear, as the fluid control volume in figure 16.

An elastic material has constant values for $E_{m}$ and $G_{m}$ under all conditions and exhibits no hysteresis when deformed. No material is elastic under all conditions - inelastic failures happen in all materials - however, vessels are much more complex than most structural materials in that they are visco-elastic. A visco-elastic material has combined viscous (i.e. flow, creep and stress relaxation while the load is applied) and also elastic properties. Creep is permanent deformation over time in response to the load while stress relaxation is a reduction in stress (applied force) over time at constant stretch. In viscoelastic vessel walls the strains are much larger in magnitude for smaller applied stresses than in structural materials. Substantial force components off-axis with respect to the orientation of tissue features, like collagen fibers and elastin plates, result in complex nonlinear strain tensors (see, for example, Humphrey ${ }^{19}$ ).

It is perhaps most helpful to reduce the complete tensor-based discussion to a few simple observations at the expense of mathematical rigor. As a simple model, vessels are approximately "thin walled pressure vessels" (figure 18). A closed vessel (i.e. closed at both ends) of radius, $r$, and thickness, $t$, with internal pressure, $P$ will have two principal stress components, a circumferential stress, $\sigma_{\mathrm{C}}\left(\mathrm{N} / \mathrm{m}^{2}\right)$ and a longitudinal stress, $\sigma_{\mathrm{L}}$ $\left(\mathrm{N} / \mathrm{m}^{2}\right)$ (in the absence of flow) given by:

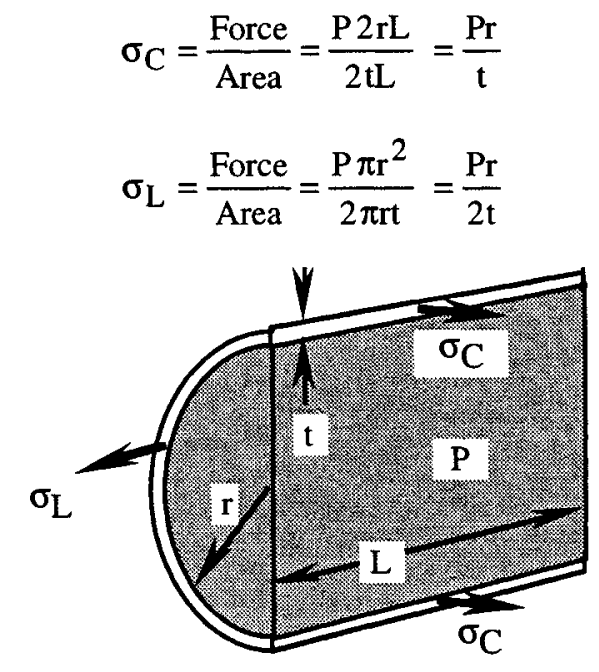

Figure 18. A blood vessel as a thin wall pressure vessel at static pressure $\mathrm{P}$ (no flow).

Notice that the static longitudinal stress is always smaller than the circumferential stress, and their relationship is fixed at a ratio of $2: 1$. We might reasonably expect that the vessel energy absorbing and structural components responsible for handling static stress would be spirally wound at a pitch angle near 27 degrees since $\tan \left(27^{\circ}\right)=0.5$. Of course, 
vessels in situ are not closed, in the static sense, and so the static analysis doesn't predict where the longitudinal stress comes from. There will be longitudinal stresses applied, even in the very low flow case, due to momentum reaction forces in the curve of the aorta, downstream pressure drops, and (mostly) to wall shear stress when blood is flowing. So, the winding angle will probably be quite different from $27^{\circ}$.

The origin of most of the shear stresses on the vessel wall in situ is the fluid shear described in equation (2), though other effects also contribute. It had been generally assumed that the wall shear stress (WSS), $\mu \partial \mathrm{u} / \partial \mathrm{x}$, was the origin of most of the adverse effects leading to vascular compromise, but new results suggest that it may in fact be the wall shear stress gradient (WSSG), $\mu \nabla^{2} \mathbf{u}$, which is actually responsible for the adverse effects induced by flow irregularities ${ }^{23}$.

Arteries may be considered, mechanically, as a mixture-composite since they are a solidfluid mixture and a composite of elastin-collagen-smooth muscle ${ }^{19}$. Most larger arteries are sized so that the mean wall stress is relatively constant, even in hypertension ${ }^{19}$. The aorta and carotid arteries are built up of layers of musculo-elastic fascicles, as first suggested by Clark and Glagov 25 . These may be seen in each of the several arteries shown in figures 2 to 13 in the previous discussion. A fascicle consists of smooth muscle cells surrounded by elastin plates and collagen bundles between the elastin sheets or plates. The number of fascicle layers increases with vessel diameter: approximately a 5 $\mu \mathrm{m}$ increase in wall thickness for each $1 \mathrm{~mm}$ increase in artery diameter ${ }^{19}$. However, as was seen in the above discussion, the distribution of collagen, elastin and smooth muscle varies significantly from vessel to vessel and between species.

Vessels are formed under load. Physiologic loading includes a significant stretch of elastin sheets even at zero pressure. If an artery is transected or resected, its length shortens typically by 30 to $50 \%$. A resected artery still has substantial residual stress. If a ring of resected artery is cut longitudinally, it will open until the net residual stress is zero; this measurement is referred to as the "opening angle", studied in some detail by Fung and co-workers $26,27,28,29$ (and several other papers). They concluded that the opening angle is relatively insensitive to the location of single radial cuts and that a single cut relieves almost all of the residual stress - this latter observation was concluded from the observation that the opening angles of single and multiple radial cuts were found to be the same. However, Vossoughi et $\mathrm{al}^{30}$ reported that if one separates an arterial ring into inner and outer portions (media and adventitia), the single and multiple cut opening angles are different for the two segments. And in very recent model studies by Van Dyke and Hoger ${ }^{31}$, it was shown that Fung's observation of identical opening angles between single and several radial cuts does not imply the absence of residual stress: the models predict that even if there is residual stress the opening angles are about the same. In any event, resecting an artery results in isovolumic shortening of the elastin (and other constituents) and, perhaps, a change in the local volume fractions, which may influence the results of opening angle measurements.

An obviously significant experiment is to measure arterial diameter as a function of internal static pressure; the rate of change in circumference is directly related to the elastic modulus in that direction. Cox ${ }^{32}$ collected data from various canine arteries at their in vivo length (a critical point in view of the tendency of arteries to shorten after resection). The resulting pressure-diameter data show a nonlinear response (as would be expected); substantial differences among the vessels, also expected; and a substantial contribution of smooth muscle to the result. Other studies by $\operatorname{Cox} 33,34,35$ are similarly illuminating. 
The wall stresses in the aorta and other vessels arise from two separate phenomena. The circumferential stress is due primarily to the internal blood pressure and the longitudinal stress primarily from fluid shear as the blood flows. The maximum circumferential stress occurs at peak pressure and the maximum longitudinal shear stress at peak flow - i.e. at two different times in the cardiac cycle. Considering the cardiac beat frequency as one cycle (where the period of the pressure wave corresponds to $360^{\circ}$ ), Qiu and Tarbell ${ }^{12}$. have determined the relative phase angles of the two stresses. Defining the phase angle between pressure distention of the vessel, $D$, and flow induced shear, $\tau$ as $\phi(D-\tau)$ :

$$
\phi(\mathrm{D}-\tau)=\phi(\mathrm{D}-\mathrm{Q})+\phi(\mathrm{Q}-\tau)
$$

where $Q$ refers to the time of maximum flow. The first term on the right hand side is the phase angle of the vessel flow "impedance", Z (complex):

$$
\mathrm{Z}=\frac{\mathrm{P}}{\mathrm{Q}} \quad|\mathrm{Z}|=\left|\frac{\mathrm{P}}{\mathrm{Q}}\right| \quad \phi_{\mathrm{Z}}=\phi_{\mathrm{P}}-\phi_{\mathrm{Q}}=\phi(\mathrm{D}-\mathrm{Q})
$$

assuming that the peak pressure occurs simultaneously with the peak distention of the vessel wall. They found in detailed model studies that at high unsteadiness (i.e. at high Womersley number, $\alpha)$ the typical phase angles were: $\phi(P-Q)=-45^{\circ}=\phi(\tau-Q)$, which means that $\phi(D-\tau)=-90^{\circ}$ in large arteries, and $\phi(D-\tau)=-45^{\circ}$ in large veins.

\subsection{Heat Transfer and Thermodynamics}

Thermodynamics is the study of different states of matter - the net result of energy exchange and material transformation - with no real consideration of the rate at which exchange and transformation take place. Heat transfer is primarily concerned with the rate at which thermal energy is exchanged. The language and mathematical formalism are quite different in the two fields and often practitioners of the two professions do not have much to say to each other. In thermal surgery we must be concerned with both points of view.

\subsubsection{Heat transfer}

Heat transfer is one of the primary functions of the circulatory system; however it turns out that as a practical matter most of it occurs in smaller vessels. There are many texts on the fundamentals of heat transfer. Perhaps a one of the more complete treatments is by DeWitt and Incropera ${ }^{36}$, though both Rosenhow and Choi ${ }^{37}$ and Krieth and Bohn ${ }^{38}$, among many others, are also quite informative and useful. The best treatment of heat transfer in the vascular system is the two volume set edited by Shitzer and Eberhart. ${ }^{40}$

Within tissues conduction heat transfer (including convection) dominates. Radiation heat can make a significant contribution at surfaces, however. It is, in fact, the signal itself when you apply thermographic imaging to estimate surface temperature. Convection is important at vessel walls and, possibly, on exposed surfaces. Kays and Crawford ${ }^{39}$ is probably the most comprehensive treatment of convection heat transfer.

Conduction heat transfer through a uniform solid slab of material of thickness $\Delta \mathrm{x}$ with constant temperatures on both faces is: 


$$
\mathrm{q}=-\mathrm{k} \frac{\Delta \mathrm{T}}{\Delta \mathrm{x}}
$$

where: $\mathrm{q}=$ heat flux $\left(\mathrm{W} / \mathrm{m}^{2}\right), \mathrm{k}=$ thermal conductivity $\left(\mathrm{W} / \mathrm{m}-{ }^{\circ} \mathrm{C}\right), \Delta \mathrm{T}=$ the temperature difference $\left({ }^{\circ} \mathrm{C}\right)$ across the slab, $\Delta \mathrm{x}=$ slab thickness $(\mathrm{m})$ and the negative sign confirms that heat flux is from high temperature to low temperature. The conduction heat flux is actually a vector field quantity, $\mathbf{q}$, in a general three-dimensional sense, and can be expressed in terms of the local temperature gradient, $\nabla \mathrm{T}$ :

$$
q=-k \nabla T
$$

Convection heat flux, $\mathrm{q}_{\mathrm{conv}}\left(\mathrm{W} / \mathrm{m}^{2}\right)$, occurs at the surfaces of blood vessels and is typically formulated as a one-dimensional flux:

$$
\mathrm{q}_{\text {conv }}=\mathrm{h}\left(\mathrm{T}_{\mathrm{w}}-\mathrm{T}_{\infty}\right)
$$

where: $h=$ the convection coefficient $\left(W / \mathrm{m}^{2}-{ }^{\circ} \mathrm{C}\right), \mathrm{T}_{\mathrm{W}}=$ the wall temperature and $\mathrm{T}_{\infty}$ is the "free stream" temperature of the fluid flowing above the surface. A flat plate in room air without any forced air flow has an effective value for $h$ between 5 and $25 \mathrm{~W} / \mathrm{m}^{2}-{ }^{\circ} \mathrm{C} .{ }^{36}$ When the air (or other fluid) is moving various functional relations are used to adjust the convection coefficient, $\mathrm{h}$, to include its velocity.

For completeness, surface infrared radiation (at body temperatures primarily between 3 and $14 \mu \mathrm{m}$ wavelength) can be formulated in a similar fashion:

$$
\mathrm{q}_{\mathrm{rad}}=\varepsilon_{\mathrm{surf}} \sigma_{\mathrm{sb}}\left(\theta_{\mathrm{w}}^{4}-\theta_{\infty}^{4}\right)
$$

where: $\mathrm{q}_{\mathrm{rad}}=$ radiation heat flux to the environment $\left(\mathrm{W} / \mathrm{m}^{2}\right), \varepsilon_{\text {surf }}=$ surface emissivity, $\sigma_{\mathrm{sb}}=$ the Stefan-Boltzmann constant $\left(5.67 \times 10^{8} \mathrm{~W} / \mathrm{m}^{2}-\mathrm{K}^{4}\right)$ and $\theta=$ the absolute temperature $(\mathrm{K})$. This relation describes only the simplest model of radiation heat to a black body environment at uniform temperature with the simplest of shape and view factors. DeWitt and Incropera ${ }^{36}$ treat the intricacies of the radiation heat problem in a readable and understandable fashion; but perhaps the most comprehensive treatment is by Siegel and Howell ${ }^{41}$.

While equation (14) is useful for a surface exposed to the atmosphere, it is not useful within the circulation, except in the largest of vessels. In a vessel the effect of the boundary layer is of prime importance - there is a thermal boundary layer similar, in most senses, to the fluid boundary layer except that it is based on the temperature gradient near the wall, $\mathrm{dT} / \mathrm{dx}$, rather than the velocity gradient of equation (2). In laminar flow, the boundary layer fills the entire vessel cross-section and the description of the overall heat transfer is more complex since heat transfer and local fluid mechanics are strongly coupled. Early treatments of this problem are Chato's analysis for single vessels and for an artery-vein pair in close proximity 42 and the study of tumor circulation effects by Chen and Holmes at about the same time ${ }^{43}$.

Most vessel-tissue and vessel-vessel heat transfer occurs in "thermally significant" vessels ${ }^{40}$. Thermally significant vessels have lengths similar to their equilibration 
length. The length of vessel required for equilibration depends on the velocity of the blood, $u$, the diameter of the vessel, $d$, the overall heat transfer coefficient, $U$ (essentially, the effective value of $h$ in equation 14 ) and the density and specific heat of the blood, $\rho_{b}$ and $c_{b}$ respectively:

$$
\mathrm{L}_{\mathrm{e}}=\frac{\mathrm{d}}{4} \frac{\rho_{\mathrm{b}} \mathrm{c}_{\mathrm{b}} \mathrm{u}}{\mathrm{U}}
$$

where: $\mathrm{L}_{\mathrm{e}}$ is in $\mathrm{m}, \rho_{\mathrm{b}}$ is in $\mathrm{kg} / \mathrm{m}^{3}, \mathrm{cb}_{\mathrm{b}}$ is in $\mathrm{J} / \mathrm{kg}-{ }^{\circ} \mathrm{C}$, $\mathrm{u}$ in $\mathrm{m} / \mathrm{s}$ and $\mathrm{U}$ in $\mathrm{W} / \mathrm{m}^{2}{ }_{-}^{\circ} \mathrm{C}$. Chen and Holmes estimate that the overall heat transfer coefficient may be found from:

$$
\mathrm{U}=\frac{2}{\Lambda} \frac{\mathrm{k}_{\mathrm{t}}}{\mathrm{d}}
$$

where: $k_{t}$ is the thermal conductivity of the tissue and, $\Lambda$ is, let's face it, a fudge factor. A useful estimate for $\Lambda$ is approximately 3 with an uncertainty of a factor of 2 (i.e. $\Lambda$ is probably somewhere between 1.5 and 6 for most vessels and tissues).

Thermally significant vessels should have diameters in the neighborhood of 300 to 350 $\mu \mathrm{m}$ or so, and lengths on the order of 9 or $10 \mathrm{~mm}$; larger than arterioles and venules but smaller than typical middle sized vessels. Larger vessels (both arteries and veins) have high flow velocities and the residence time of blood control volumes is too short to exchange significant heat across the diameter. Smaller vessels (arterioles, venules and capillaries) have longer residence times, but the blood comes quickly into thermal equilibrium with the surrounding tissues. Blood flow (perfusion) in these small vessels may actually be modeled as an increase in effective thermal conductivity in the direction of blood flow as a result, the so-called $\mathrm{k}$-effective, $\mathrm{k}_{\mathrm{eff}}$, model. The properties of the several vascular compartments have been determined ${ }^{44}$ and are summarized in Table 4

\begin{tabular}{ccccc} 
Vessel & $\begin{array}{c}\text { \% of Vascular } \\
\text { Volume }\end{array}$ & Radius $(\mathrm{mm})$ & $\mathrm{L}_{\mathrm{e}}(\mathrm{mm})$ & $\mathrm{l} / \mathrm{L}_{\mathrm{e}}$ \\
\hline \hline Aorta & 3.30 & 5.0 & $1.9 \times 10^{5}$ & 0.002 \\
Large artery & 6.59 & 1.5 & 4000 & 0.05 \\
Arterial branch & 5.49 & 0.5 & 300 & 0.3 \\
Terminal branch & 0.55 & 0.3 & 80 & 0.1 \\
Not Identified & 1.0 & 0.175 & 9 & 1 \\
Arteriole & 2.75 & 0.01 & 0.005 & 400 \\
Capillary & 6.59 & 0.004 & 0.0002 & 6000 \\
Venule & 12.09 & 0.015 & 0.002 & 800 \\
Terminal Vein & 3.30 & 0.75 & 100 & 0.1 \\
Venous branch & 29.7 & 1.2 & 300 & 0.3 \\
Large vein & 24.2 & 3.0 & 5000 & 0.04 \\
Vena cava & 5.49 & 6.25 & $1.9 \times 10^{5}$ & 0.002
\end{tabular}

Table 4. Properties of vascular compartments adapted from ${ }^{44}$. However, please note that the dimensions are relative. For example, capillaries can be longer than $200 \mu \mathrm{m}$. 
Matching the Energy Source to the Clinical Need / 251

\subsubsection{Thermodynamics}

The thermodynamic state of a material is completely described by specifying any two of the six state variables: temperature, $T$, pressure, $P$, density, $\rho$ (or its inverse, the specific volume, $v=1 / \rho)$, enthalpy, $H(J)$, internal thermal energy, $U(J)$, and entropy, $S\left(J /{ }^{\circ} C\right)$. The state variables are inter-related by Maxwell's relations. So, for example, the enthalpy is the sum of internal thermal energy and the P-v product (i.e. the "flow work"):

$$
\mathrm{H}=\mathrm{U}+\mathrm{mPv}=\mathrm{mcT}+\mathrm{Pm} / \mathrm{p}
$$

where: $m$ is the mass of material and $c$ is the specific heat. We heat blood vessels and other tissues to achieve some therapeutic change of state: promotion of tissue perfusion, analgesia, desiccation, irreversible alteration of tissue proteins, deactivation of tissue enzymes, and apoptosis are examples. The energy source raises the temperature in a fashion described by the first law of thermodynamics - (energy in - energy out) is stored in the internal thermal energy within the volume:

$$
\mathrm{mc} \Delta \mathrm{T}=\text { Energy in }- \text { Energy out }
$$

where $\Delta \mathrm{T}$ is the temperature change. Energy flows across the boundaries of the control volume by heat transfer, work, mass transfer and phase transformation. We usually express these various terms in the point form, rather than in the integral form, since we are concerned with highly localized phenomena. For example, a first law continuity relation considering only net conduction heat transfer in the integral (volume) form is:

$$
\frac{\partial}{\partial t}\left(\iiint_{\text {vol. }} \rho c \mathrm{c}(\mathrm{x}, \mathrm{y}, \mathrm{z}) \mathrm{dxdydz}\right)=-\oint_{\Sigma}(-\mathrm{k} \nabla \mathrm{T}) \cdot \mathrm{d} \mathbf{S}
$$

where the left hand side is the rate of increase in the internal thermal energy, the closed surface, $\Sigma$, defines the control volume of integration, and $\mathrm{d} S$ is the vector surface normal pointing outwards from the surface (figure 19a).

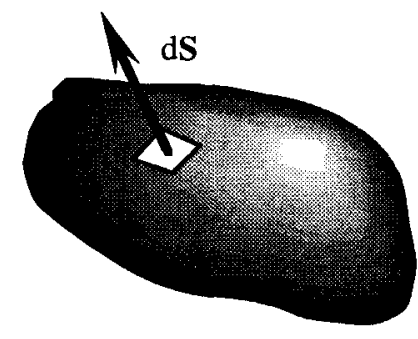

(a)

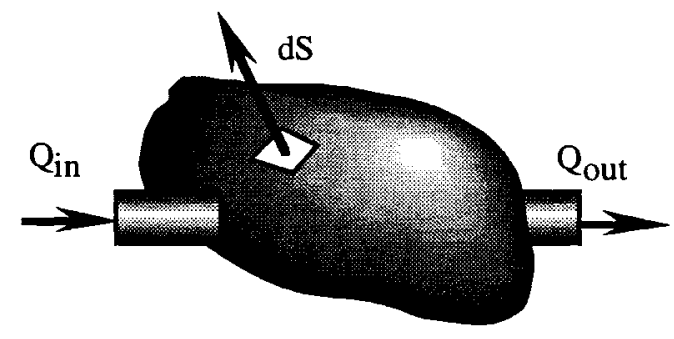

(b)

Figure 19. Energy balance calculation for a finite control volume of tissue defined by the closed surface $\Sigma$. (a) Considering conduction heat transfer only, as in equation 20a. (b) The tissue as an open system with blood flow in, $Q_{\text {in }}\left(\mathrm{m}^{3} / \mathrm{s}\right)$, and out, Qout $\left(\mathrm{m}^{3} / \mathrm{s}\right)$ contributing flow work and fluid enthalpy.

This relation may be reduced to the point form for numerical modeling purposes by applying the divergence theorem: 


$$
\rho c \frac{d T}{d t}=\nabla \cdot(k \nabla T)=k \nabla^{2} T
$$

In tissues the first law must be augmented to specifically include tissue metabolic heat and the effects of blood perfusion (figure 19b). Blood flow energy terms can be significant even if the vessel is not one of the "thermally significant" vessels:

$$
\begin{gathered}
\text { Energy In }=Q_{\text {in }} \rho_{b} c_{b}\left(T_{b} \text { in }-T\right) \\
\text { Energy Out }=Q_{\text {out }} \rho_{b} c_{b}\left(T_{b} \text { out }-T\right)
\end{gathered}
$$

where the $b$ subscript refers to blood thermal properties and $T$ is the tissue temperature.

The original formulation of the first law for tissues, which included the flow enthalpy, was the so-called "bioheat equation" by Pennes ${ }^{45}$ in 1948:

$$
\rho c\left[\frac{\partial T}{\partial t}\right]=k \nabla^{2} T+q_{g e n}+q_{m}+w \rho_{b} c_{b}\left(T_{a}-T\right)
$$

where: $q_{g e n}$ has been added for this paper and is the volumetric power deposition rate from the heating source $\left(\mathrm{W} / \mathrm{m}^{3}\right), \mathrm{qm}_{\mathrm{m}}$ is the metabolic heat $\left(\mathrm{W} / \mathrm{m}^{3}\right)$, w is the tissue perfusion in $\left(\mathrm{kg}_{\text {blood }} / \mathrm{kg}_{\text {tissue }}-\mathrm{s}\right), \mathrm{T}_{\mathrm{a}}$ the arterial temperature, $\mathrm{T}$ the temperature of the infinitesimal volume of surrounding tissue and, again, the b subscript refers to blood properties. Pennes results were derived by assuming that the arterial blood comes to thermal equilibrium while in the tissue volume - this is a supportable assumption in arterioles, capillaries and venules; and is useful in analogous heat transfer situations ${ }^{46,47}$. The result has proven quite controversial in that gross simplifying assumptions were employed which are not at all compatible with the details of circulatory heat transfer as discussed above. In a seminal series of papers Weinbaum formulated an elegant alternative approach to handle the general case ${ }^{48,49}$, but it is difficult to implement unless significant details of the precise distribution of blood perfusion and vessel dimensions are well-defined in the tissue. These issues are of substantial significance when large volumes of tissue are to be heated for analgesia or, especially, in tumor treatment by hyperthermia therapy where elevation to a precise steady state therapeutic temperature range for extended time periods is essential. In tumor heating one must precisely balance applied power deposition with local perfusion and heat conduction to achieve steady state.

For thermal surgery purposes we are applying significant external heating to irreversibly alter tissues after a significant temperature rise. Putting aside the cases of therapeutic heating at low temperatures for analgesia and the like, phase change and power generation by the surgical heat source are the most important terms and dominate metabolic heat and tissue perfusion heat transfer by several orders of magnitude. So:

$$
\rho c\left[\frac{\partial T}{\partial t}\right]=k \nabla^{2} T+q_{g e n}+q_{f g}-\text { surface losses }
$$


where: $\mathrm{q}_{\mathrm{fg}}$ is the phase change heat (expressed as $\mathrm{W} / \mathrm{m}^{3}$ ), and "surface losses" represent radiation loss and convective heat transfer into the blood and/or the atmosphere.

\subsubsection{Thermal damage processes}

The effect of elevated temperatures is to obtain an irreversible change in the vessel tissues, collectively described here as thermal damage. Kinetic models of thermal damage processes based on an Arrhenius formulation have been used for many years to describe different forms of thermal damage $50,51,52$. In standard thermal damage process descriptions the endpoint damage, $\Omega$, is expressed as the time integral of the damage accumulation rate:

$$
\Omega(\tau)=\ln \left\{\frac{\mathrm{C}(0)}{\mathrm{C}(\tau)}\right\}=\int_{0}^{\tau} \mathrm{A} \mathrm{e}^{\left[\frac{-\mathrm{E}}{\mathrm{RT}}\right]} \mathrm{dt}
$$

where: $\Omega$ is the damage parameter (dimensionless), $C$ the concentration of undamaged tissue constituent, A the "frequency factor" $\left(\mathrm{s}^{-1}\right)$ is a measure of the collision frequency between molecules, $\mathrm{E}$ is an energy barrier which must be overcome by the native state molecules in order to denature $(\mathrm{J} / \mathrm{mole}), \mathrm{R}$ the gas constant $\left(8.3143 \mathrm{~J} / \mathrm{mole}-{ }^{\circ} \mathrm{K}\right)$, $T$ the absolute temperature (K), and $t$ is the time (s). Assumptions in this model are that: 1) a single damage process is under consideration (thus one pair of coefficients suffices), and 2) the damage process follows approximately first order kinetics. A discussion of the origins and physical significance of the various components of the damage model may be found in section 4.4 of the Handbook of Thermal Engineering written by Diller, Pearce and Valvano ${ }^{53}$.

\begin{tabular}{|c|c|c|c|}
\hline Tissue/Reference & $A(s-1)$ & $\mathrm{E}(\mathrm{J} / \mathrm{mole})$ & Conditions \\
\hline \multicolumn{4}{|l|}{ Retina } \\
\hline \multirow[t]{3}{*}{ Takata et al ${ }^{54}$} & 0 & & $\mathrm{~T} \leq 316 \mathrm{~K}$ \\
\hline & $4.3 \times 10^{64}$ & $4.2 \times 10^{5}$ & $316<\mathrm{T} \leq 323 \mathrm{~K}$ \\
\hline & $9.3 \times 10^{104}$ & $6.7 \times 10^{5}$ & $\mathrm{~T}>323 \mathrm{~K}$ \\
\hline Welch \& Polhamus 55 & $3.1 \times 10^{99}$ & $6.28 \times 10^{5}$ & \\
\hline Birngruber 56 & $10^{44}$ & $2.93 \times 10^{5}$ & \\
\hline \multicolumn{4}{|l|}{ Skin } \\
\hline Henriques 57 & $3.1 \times 10^{98}$ & $6.28 \times 10^{5}$ & \\
\hline Weaver \& Stoll ${ }^{58}$ & $2.2 \times 10^{124}$ & $7.83 \times 10^{5}$ & $\begin{array}{l}317<\mathrm{T}<323 \mathrm{~K} \\
\mathrm{~T} \geq 323 \mathrm{~K}\end{array}$ \\
\hline \multicolumn{4}{|r|}{$--1+2+2-5$} \\
\hline \multirow[t]{2}{*}{ Yang et $\mathrm{al}^{59}$} & $3.8 \times 10^{57}$ & $3.85 \times 10^{5}$ & White \\
\hline & $3.05 \times 10^{56}$ & $3.89 \times 10^{5}$ & Yolk \\
\hline \multicolumn{4}{|l|}{ Collagen } \\
\hline Agah $^{60}$ & $5.6 \times 10^{63}$ & $4.3 \times 10^{5}$ & Aorta \\
\hline Pearce et al ${ }^{61}$ & $1.606 \times 10^{45}$ & $3.06 \times 10^{5}$ & Rat skin \\
\hline
\end{tabular}

Table 5. Damage model parameters from various sources.

The damage process coefficients, $\mathrm{A}$ and $\mathrm{E}$, must be derived from experimental data and are specific to the particular damage endpoint under study. The physical significance of the damage parameter, $\Omega$, is that it is the logarithm of the ratio of original concentration of 
undamaged material, $C(0)$, to the remaining undamaged material at the end of heating, $C(\tau)$. A threshold experiment is one for which $\Omega=1$; A is then obtained from the intercept and $\mathrm{E}$ from the slope on an Arrhenius plot of $\ln (\tau) v s .1 / \mathrm{T}$ for the threshold experiments. A threshold experiment exhibits significant thermal damage since $\mathrm{C}(\tau)=$ $36.8 \%$ - or $63.2 \%$ of the vessel wall material has been damaged. Working estimates of representative damage coefficients are contained in Table 5. Additionally, Kang et al 62 have measured heat-induced changes in coronary artery wall, but have not extracted $A$ and $E$ values from the data.

\subsubsection{Water vaporization}

Water is by far the most thermodynamically active tissue constituent, and for temperatures above about $90{ }^{\circ} \mathrm{C}$ water behavior dominates other observed thermal phenomena. Expansion of the water, whether or not phase change takes place, accounts for most of the internal stresses applied to tissue. Above the saturation temperature (100 ${ }^{\circ} \mathrm{C}$ at standard pressure), the vaporization process becomes a volumetric energy sink in which phase change can generate high local pressures and tissue stresses. At extreme heating rates in tissue and/or in free water, such as are realized by extremely short pulsed laser activations, the water may become metastable where the vaporization is rate-limited with rate coefficients (similar to $\mathrm{A}$ and $\mathrm{E}$ above) determined by the supersaturation ratio, $\mathrm{P} / \mathrm{P}_{\text {sat }}$, and the surface free energy of nucleated vapor bubbles in the liquid phase. In the rapid ablation case the energy powering the debris plume probably comes from rapid water phase changes.

\subsubsection{Evaporation}

At lower temperatures water effects are still important since all tissues exposed to air will lose water vapor to the atmosphere. Below the saturation temperature at local atmospheric pressure - i.e. below $100^{\circ} \mathrm{C}$ at sea level- water evaporates from exposed surfaces due to the difference between the vapor pressure (the saturation pressure) at the surface temperature and the partial pressure of water vapor in the atmosphere. The vapor pressure at temperature may be found from thermodynamic tables or estimated from a polynomial fit (original data from Keenan and Keyes ${ }^{63}$ ):

$$
\begin{aligned}
\mathrm{P}_{\text {sat }}= & -43.2+2.39 \mathrm{~T}-0.0362 \mathrm{~T}^{2}+2.41 \times 10^{-4} \mathrm{~T}^{3} \\
& +6.68 \times 10^{-8} \mathrm{~T}^{4}+1.69 \times 10^{-9} \mathrm{~T}^{5}
\end{aligned}
$$

where: $\mathrm{P}_{\text {sat }}$ is the saturation pressure (in $\mathrm{kPa}$ ) and $\mathrm{T}$ is the temperature $\left({ }^{\circ} \mathrm{C}\right.$ ). The relative humidity is the ratio of the actual air water vapor pressure to the saturation pressure of water at the air temperature. Below $100^{\circ} \mathrm{C}$ (the saturation temperature) at atmospheric pressure, $100.1 \mathrm{kPa}$, water vaporization is a diffusion-limited surface loss phenomenon and depends primarily on surface characteristics such as local humidity and temperaturedependent mass diffusion coefficients. A useful means to estimate surface water evaporation is Snelling's formula ${ }^{64}$, which was derived from experimental measurement of evaporation rates from solar ponds:

$$
\zeta=\left(7.31 \times 10^{-11}+1.2 \times 10^{-11} \mathrm{u}_{\infty}\right)\left(\mathrm{P}_{\mathrm{sat}}-\mathrm{P}_{\mathrm{atm}}\right)
$$

where: $\zeta$ is the evaporation rate in meters of water depth/s, $\mathrm{u}_{\infty}$ is the free stream velocity of air $7.5 \mathrm{~m}$ above the surface, $P_{\text {sat }}$ is the saturation vapor pressure of the water at temperature and $\mathrm{P}_{\mathrm{atm}}$ is the vapor pressure of water in the atmosphere (i.e. the relative 
humidity times the water saturation pressure at the air temperature). Surface water vaporization typically dominates surface radiation and convection losses and bulk tissue loss terms above about $60^{\circ} \mathrm{C}^{65}$.

\subsubsection{Boiling processes}

In order to include the effects of boiling in the energy balance, the left hand side of equation (23) must be modified. Neglecting surface losses and allowing changes in pressure and density of the tissue in the enthalpy on the left hand side we obtain:

$$
\frac{\partial}{\partial t}\{\rho h\}=\nabla \cdot(k \nabla T)+q_{g e n}-q_{f g}
$$

where the specific enthalpy, $\mathrm{h}(\mathrm{J} / \mathrm{kg})$, includes internal thermal energy and flow work and $\mathrm{q}_{\mathrm{fg}}$ is the energy of phase change due to boiling (or evaporation) in $\left(\mathrm{W} / \mathrm{m}^{3}\right)$. This model may be recast in terms of the rate of local temperature rise (as in equation 23) to facilitate numerical implementation if two thermodynamic parameters can be evaluated, $\partial \mathrm{P} / \partial \mathrm{T}$ and $\partial \rho / \partial \mathrm{T}$ :

$$
\left\{\rho \mathrm{c}+\frac{\partial \mathrm{P}}{\partial \mathrm{T}}-\frac{\mathrm{P}}{\rho} \frac{\partial \rho}{\partial \mathrm{T}}\right\} \frac{\partial \mathrm{T}}{\partial \mathrm{t}}=\nabla \cdot(k \nabla \mathrm{T})+\mathrm{q}_{\mathrm{gen}}-\frac{\partial \mathrm{m}}{\partial \mathrm{t}} \mathrm{h}_{\mathrm{fg}}(\mathrm{T})
$$

where: $\partial \mathrm{m} / \partial \mathrm{t}$ is the mass rate of phase change per unit volume of tissue $\left(\mathrm{kg} / \mathrm{s}-\mathrm{m}^{3}\right)$ and $\mathrm{h}_{\mathrm{fg}}$ is the phase change enthalpy $(\mathrm{J} / \mathrm{kg})$. The saturation density curve, a fifth order polynomial fit from 20 to $374{ }^{\circ} \mathrm{C}$ is approximately (original data from Keenan and Keyes ${ }^{63}$ ):

$$
\begin{aligned}
\rho_{\text {sat }}= & 1026-1.41 \mathrm{~T}+0.0191 \mathrm{~T}^{2}-1.65 \times 10^{-4} \mathrm{~T}^{3} \\
& +5.594 \times 10^{-7} \mathrm{~T}^{4}-6.918 \times 10^{-10} \mathrm{~T}^{5}
\end{aligned}
$$

where: $\rho_{\mathrm{sat}}$ is in $\left(\mathrm{kg} / \mathrm{m}^{3}\right)$ and is $\mathrm{T}$ the temperature $\left({ }^{\circ} \mathrm{C}\right)$. The required term $\partial \rho / \partial \mathrm{T}$ can readily be calculated from this relation. Similarly, from the same source, the phase change enthalpy as a function of temperature is (original data from Keenan and Keyes ${ }^{63}$ ):

$$
\mathrm{h}_{\mathrm{fg}}=2.623 \times 10^{6}-8970 \mathrm{~T}+0.8535 \mathrm{~T}^{3}+0.2723 \mathrm{~T}^{4}-3.243 \times 10^{-6} \mathrm{~T}^{5}
$$

where: $\mathrm{h}_{\mathrm{fg}}$ is in $(\mathrm{J} / \mathrm{kg})$ and $\mathrm{T}$ is the temperature $\left({ }^{\circ} \mathrm{C}\right)$.

In free liquid phase water which is not constrained by rigid or visco-elastic tissue structures, $\partial \mathrm{P} / \partial \mathrm{T}$ is negligibly small except for extremely short laser activations or electrosurgical arcs. The density change term cannot be neglected in free water, however. This additional term (when phase change is included) accounts for the kinetic energy imparted to the plume when water vaporization is rapid and significant. It also contains the origin of acoustic waves in tissue whether or not phase change is significant. For no vaporization, an estimate of $\partial \rho / \partial \mathrm{T}$ can be obtained from the saturation density vs. temperature curve under the valid assumption that the liquid phase water density is primarily determined by temperature rather than local pressure. 
A model based on the energy balance of equation (28), should use a small time step so that the contributions of local heat transfer may be calculated and summed with the volume power term. When the vaporization process is not rate-limited, excess energy above that required to maintain a constant temperature may be imagined to go into the vaporization process at the local temperature and pressure. The effect of vaporization on the local pressure may be calculated if an acceptable model for tissue mechanical response is available. Note that at $120^{\circ} \mathrm{C}$ the saturation pressure (equation 25 ) is already up to 2 atmospheres $(200.2 \mathrm{kPa})$ and climbs precipitously above that. When external energy, qgen, is added faster than evolved water vapor can diffuse through tissue to maintain liquid saturation $(100 \mathrm{C})$ and atmospheric pressure $(100.1 \mathrm{kPa})$, the tissue temperature readily exceeds $100^{\circ} \mathrm{C}$, which increases the local tissue pressure (thus the saturation temperature) and lowers the phase change enthalpy (equation 29). In a numerical model of slow heating one may usually assume that vaporization occurs at local saturation conditions (equilibrium thermodynamics applies) with rate determined by excess heating energy (that is, energy in excess of that consumed by conduction heat transfer and other losses) and thermodynamic properties.

The mechanical constraints on intracellular water are significant. Extracellular expanded water and water vapor needs only to "percolate" through spaces in the gross structure while intracellular water vapor expands cell volume putting stress on the cell membrane. The applied stresses, both intracellular and extracellular, create a thin wall pressure vessel problem. In many cases the local pressure increases cause rupture in the tissue structure, histologically observable as the "popcorn" effect - communicating vacuoles of thin remnants of cell structure in large void spaces. Elevated tissue pressures also explain the readily observed tearing phenomena in highly layered tissues. These steam vacuoles are sometimes mis-identified as adipose tissue in histologic sections owing to the similarities in appearance.

\subsubsection{Rate-limited vaporization: nucleate boiling}

The problem of extremely rapid boiling has been well studied 66,67 . Under ordinary conditions there is a plentiful supply of nucleating centers for boiling to initiate and thus the equilibrium boiling approach is sufficient for most purposes. In the case of extremely short activations (lasers or RF power) in free water, or in the case of a laser source for which the primary chromophore is water, the boiling may happen in the absence of a nucleating site for the bubbles. This is described as nucleate boiling in which the external energy is used to create a bubble in uniform liquid phase water. To form a critically sized bubble a sufficient number of liquid phase molecules must jump to vapor phase. A bubble of critical radius, $\mathbf{r}_{\text {crit }}$, has a $50 \%$ probability of growing or of collapsing back to liquid phase. This radius is small enough that the energy stored in surface tension is quite large:

$$
r_{\text {crit }}=\frac{2 \sigma_{\text {fg }}}{P_{\text {sat }}-P}
$$

where: $\sigma_{\mathrm{fg}}(\mathrm{N} / \mathrm{m})$ is the surface tension at the liquid temperature and the liquid pressure, $P$, is less than $P_{s a t}$ at the liquid temperature because the liquid phase is metastable (i.e. super-saturated). Two energy barriers must be overcome, similar to the one surmounted in the Arrhenius damage model of equation (24) to form a critically sized bubble. A liquid phase water molecule must jump the kinetic barrier to vapor phase $\left(\mathrm{h}_{\mathrm{fg}}\right)$ and also 
overcome the surface tension of the bubble-liquid interface. There are thus two exponential energy barriers in nucleation theory:

$$
J_{\text {nucl. }}=Z_{1} e^{\left[\frac{-h_{f g}}{M R T}\right]} \sqrt{\frac{6 \sigma_{f g}}{(3-b) \pi m}} e^{\left(\frac{-16 \pi \sigma_{f g}^{3}}{3 k T\left(P_{s a t}-P\right)^{2}}\right)}
$$

where: $J_{\text {nucl. }}=$ the rate of formation of critically sized bubbles (number $/ \mathrm{s}-\mathrm{m}^{3}$ ), $\mathrm{Z}_{1}=$ number of molecules/unit volume $=\rho \mathrm{N}_{\mathrm{A}} /(0.018)$ for water and $\mathrm{N}_{\mathrm{A}}=6.023 \times 10^{23}, \mathrm{M}$ is the number of moles per unit mass, $m$ is the mass per molecule $=18 / \mathrm{N}_{\mathrm{A}}$ grams for water, and $b$ is the super-saturation ratio: $b=\left(P_{\text {sat }}-P\right) / P_{\text {sat }}$. Only a few degrees of superheat are necessary to have extremely high rates of critical bubble formation. Once a nucleating center is formed it grows to larger size depending on the relationship between the internal bubble pressure and the saturation pressure of the liquid phase at its temperature.

\section{ELECTRICAL PROPERTIES OF VESSELS}

Tissues in general, and vessels in particular, are both semiconductors and lossy dielectric materials. At microwave frequencies (between about $500 \mathrm{MHz}$ and $10 \mathrm{GHz}$ ) the dominant power deposition mechanism is by losses during dipole rotation of water molecules in the microwave electric field. The ISM (Industrial, Scientific and Medical) frequencies of practical use in this range are $915 \mathrm{MHz}$ and $2.45 \mathrm{GHz}$. At radio frequencies $(6.78,13.56$ and $27.12 \mathrm{MHz}$ ) and below, the dominant heating mechanism is by "Joule" or resistive heating. The frequency range typical of electrosurgery is about $500 \mathrm{kHz}$ to $5 \mathrm{MHz}$, and all such applications are likewise governed by resistive heating. Heating by direct absorption in a magnetic field is not important in tissues since, for all practical purposes, the tissues have the same permeability as free space. Yet, tissues heat well in a radio frequency magnetic field. This is because the radio frequency magnetic field induces an electric field (by Faraday's Law of Induction) and the tissues are actually heated by the dominant electric field loss mechanism.

\subsection{The Volume Power Generation Term}

From inspection of the Poynting Power Theorem (see for example Paris and Hurd ${ }^{68}$, or Roussy and Pearce ${ }^{69}$ ), the divergence of the power density in an electric field expressed in the frequency domain is:

$$
\nabla \cdot \mathbf{S}=\mathbf{E} \cdot \mathbf{J}+j \omega \mathbf{E} \cdot \mathbf{D}=(\sigma+j \omega \varepsilon)|\mathbf{E}|^{2}
$$

where: $\mathbf{S}=$ power density $\left(\mathrm{W} / \mathrm{m}^{2}\right)$ in the electromagnetic wave, $\mathbf{E}=$ electric field vector $(\mathrm{V} / \mathrm{m}), \mathrm{J}=$ current density $\left(\mathrm{A} / \mathrm{m}^{2}\right), \omega=$ angular frequency $(\mathrm{r} / \mathrm{s}), \mathbf{D}=$ electric flux density $\left(\mathrm{C} / \mathrm{m}^{2}\right), \sigma=$ electric conductivity $(\mathrm{S} / \mathrm{m})$ and $\varepsilon=$ electric permittivity $(\mathrm{F} / \mathrm{m})$. The power density has both real and imaginary parts, of which the real part represents heating and the imaginary part energy storage (for wave propagation). The volume generation heating term, qgen, is: 


$$
\mathrm{q}_{\text {gen }}=\left(\sigma+\omega \varepsilon_{\mathrm{r}}^{\prime \prime} \varepsilon_{0}\right)|\mathbf{E}|^{2}
$$

where: $\varepsilon_{\mathrm{r}}$ " is the "loss factor", the imaginary part of the relative permittivity, and $\varepsilon_{0}$ is the permittivity of free space, $8.854 \times 10^{-12}(\mathrm{~F} / \mathrm{m})$. The first term represents Joule (resistive) heating and the second term lossy dielectric heating. The power generation term for equation (23) may be calculated when the respective properties and local electric field are known.

At lower radio frequencies typical of electrosurgery the electric field may be estimated by applying the quasi-static assumption. The maximum dimensions of any practical problem are much shorter than the wavelength in tissues; thus, the Laplace equation may be solved subject to appropriate boundary conditions to estimate the quasi-static potential field, $V(x, y, z)$ :

$$
\nabla^{2} \mathrm{~V}=0
$$

and the electric field estimated from the gradient of the potential:

$$
\mathbf{E}=-\nabla \mathbf{V}
$$

At microwave frequencies it is usually necessary to solve the complete set of Maxwell's equations to determine the electric field in tissues. Methods for estimating electric field distributions in microwave fields have been extensively studied; a description and critical review of the various techniques may be found in Roussy and Pearce ${ }^{69}$.

As a practical matter, numerical models must be used to study heating in vessels because of their complex structure and response. It is important to keep in mind that numerical models are almost never able to accurately predict specific experimental results owing to uncertainty in physical properties and randomness in tissue structure. However, they do permit study of the governing processes on fine spatial and temporal scales which cannot be obtained in experiments. When numerical models are sufficiently well behaved they can be used to study transient micro-structural thermodynamic events, and to compare dominant processes and effects. They can be used to provide substantial insight into the clinical problem.

\subsection{Electrical Permittivity and Conductivity}

At microwave frequencies the electrical property of interest is the loss factor, which is dominated by the tissue water. No published values of loss factor measurements specific to vessels could be located. Some data for other tissue types are summarized in Table 6. Useful working estimates of the loss factor may be obtained from simple volume fraction mixture formula:

$$
\varepsilon_{\mathrm{m}}^{*}=\vartheta \varepsilon_{1}^{*}+(1-\vartheta) \varepsilon_{2}^{*}
$$

where: $\mathrm{m}$ refers to the mixture, $\vartheta$ is the volume fraction of material 1 dispersed uniformly in material 2 and $\varepsilon^{*}$ is the complex permittivity, $\varepsilon^{*}=\varepsilon^{t}-\mathrm{j} \varepsilon^{\prime \prime}$. Vessels are typically about $55 \%$ by volume water and the loss factor for water over these frequencies is $\varepsilon_{\mathrm{r}}{ }^{\prime \prime}=$ 16 to 18. Losses at microwave frequencies in the non water parts of the vessel are 
relatively small because the protein molecules are too large to rotate in the electric fields. So, other losses may be ignored in calculations with little error.

\begin{tabular}{cccc} 
Tissue & $\begin{array}{c}\text { Conductivity } \\
\text { (S/m) }\end{array}$ & Permittivity, $\varepsilon^{\prime}$ & Loss Factor, $\varepsilon^{\prime \prime}$ \\
\hline \hline Fat & 0.05 to 0.09 & 3.9 to 7.2 & 0.67 to 1.4 \\
Muscle & 0.1 to 1.0 & 45 to 48 & 13 to 13.9 \\
Bone & 0.006 to 0.05 & 4.2 to $5.8^{\mathrm{a}}$ & 0.7 to $1.3^{\mathrm{a}}$
\end{tabular}

Table 6. Relative electric permittivity ${ }^{71}$ and conductivity ${ }^{72}$ of representative tissues. $\mathrm{a}_{\text {Measured in bone marrow. }}$

At radio frequencies the heating is dominated by resistive heating for which the electrical conductivity is the parameter of interest. The electrical conductivities of representative vessels and model tissues were estimated from tetrapolar impedance measurements in an approximately uniform electric field and are described by Pearce et al ${ }^{70}$ with properties of elastin and collagen determined by measurements on ligamentum nuchae and dura mater, respectively. Details of the measurement methods may be found in the reference ${ }^{70}$. The results are summarized in Table 7.

There is no significant difference between electrical conductivities at the representative electrosurgical frequencies of $500 \mathrm{kHz}$ and $2 \mathrm{MHz}$, as was expected. As reflected by the standard deviations, the uncertainty in the transverse measurements is uniformly smaller than for the longitudinal measurements, as expected from preliminary estimates. Unexpectedly, there is no significant difference between the longitudinal and transverse conductivities of canine femoral artery. The other tissues studied exhibited significant anisotropy, with the longitudinal conductivity typically about twice that of the transverse conductivity.

\begin{tabular}{ccc}
\multicolumn{4}{c}{ Electrical Conductivity (S/m) } & (S.D.) \\
\hline \hline Tissue & $500 \mathrm{kHz}$ & $2 \mathrm{MHz}$ \\
\hline Canine Femoral Artery (trans) & $0.75(0.03)$ & $0.85(0.05)$ \\
Canine Femoral Artery (long) & $0.64(0.12)$ & $0.70(0.11)$ \\
Canine Femoral Vein (trans) & $0.57(0.10)$ & $0.60(0.11)$ \\
Canine Femoral Vein (long) & $1.04(0.18)$ & $1.05(0.17)$ \\
Bovine Dura Mater (trans) & $0.26(0.05)$ & $0.27(0.05)$ \\
Bovine Dura Mater (long) & $0.41(0.17)$ & $0.43(0.17)$ \\
Bovine Ligamentum N. (trans) & $0.67(0.02)$ & $0.68(0.02)$ \\
Bovine Ligamentum N. (long) & $0.99(0.14)$ & $1.00(0.14)$
\end{tabular}

Table 7 Longitudinal and transverse electrical conductivity at room temperature. Values are averages of five samples and (standard deviation) 70 .

The electrical conductivity of a semiconductor is the product of its charge per unit volume and mobility of the charge carriers:

$$
\sigma=p|q| \mu_{p}
$$

where: $p$ is the number density of charge carriers, number $/ \mathrm{cm}^{3}, q$ is the charge of an electron (C), and $\mu_{\mathrm{p}}$ is the mobility $\left(\mathrm{cm}^{2} / \mathrm{V}-\mathrm{s}\right)$. The mobility of charge carriers in 
solution increases with increasing temperature with the result that the conductivity increases about $1.5 \% /{ }^{\circ} \mathrm{C}$ temperature rise [reference ${ }^{71}$ and others], so that:

$$
\sigma \approx \sigma_{0} \mathrm{e}^{0.015\left[\mathrm{~T}-\mathrm{T}_{0}\right]}
$$

where $\sigma_{0}$ is the conductivity at temperature $T_{0}$. Failure to account for even the difference between room temperature and body temperature can result in significant measurement errors (about 20\%).

\section{OPTICAL PROPERTIES OF VESSELS}

Another important tissue heating technology is laser heating. In contrast to electrical properties, the optical properties of many tissues vary over several orders of magnitude throughout the visible and infrared wavelengths. This may be a little surprising since the index of refraction is, in fact, the square root of the electric permittivity relative to water and since the previous discussion on microwave properties is water-dominated. However, at optical frequencies the energy modes which interact with the irradiation are vibrational rather than rotational, and many more of the cellular constituents participate in the absorption process. Interacting cellular constituents are "chromophores" and they absorb light wavelengths to widely varying degrees. Also, in contrast with radio and microwave frequencies, scattering is often a dominant process at optical frequencies. The relative importance of scattering and absorption is extremely sensitive to wavelength and accurate calculations of light propagation in tissue are difficult.

\subsection{The Volume Power Generation Term}

A few underlying concepts are important in describing laser-tissue interactions. The radiant intensity of a light beam is the power in the beam per unit solid angle (W/sr) at the angle at which it is measured - the beam irradiance $\left(\mathrm{W} / \mathrm{m}^{2}\right)$ at the tissue surface is sometimes referred to as the beam intensity, but this is incorrect. There are $4 \pi$ sterradians (sr) in a sphere - a ster-radian is a spherical version of the planar radian where there are $2 \pi$ radians in a circle. The radiance at a point in tissue, $\mathrm{L}$, is the radiant power per unit area per unit solid angle in the direction of the light beam $\left(\mathrm{W} / \mathrm{m}^{2}\right.$-sr). The light energy which heats the tissue may come from any angle, so the "fluence rate", $\Phi\left(\mathrm{W} / \mathrm{m}^{2}\right)$ in the tissue is the sum of all the radiance at the point, $(x, y, z)$, in the tissue:

$$
\Phi(x, y, z)=\oint_{4 \pi} L(x, y, z, \Omega) d \Omega
$$

where: $\Omega$ denotes the solid angle over which the integral is calculated.

The volume power generation term is obtained from the local fluence rate, $\Phi\left(\mathrm{W} / \mathrm{m}^{2}\right)$, and the absorption coefficient, $\mu_{\mathrm{a}}\left(\mathrm{m}^{-1}\right)$ is:

$$
\mathrm{q}_{\text {gen }}=\mu_{\mathrm{a}} \Phi
$$

An interesting phenomenon of importance in vessels is the effect of light scattering. Calculating the local fluence rate can be quite complicated when scattering is important. Perhaps the most comprehensive treatment of the physical aspects laser-tissue interaction 
is that of Welch and vanGemert ${ }^{73}$. Wolbarsht ${ }^{74}$ is another useful reference which contains, in addition, a thorough description of the clinical applications of lasers. There are many other treatments of the topic which can be obtained from this very meeting. The most common and effective approach to fluence rate estimation is numerical modeling since the calculations are intricate and tissues are inhomogeneous and anisotropic.

The most common application of optical measurements in clinical medicine is the use of light absorbance to determine blood chemistry. The solutions are very dilute and have been treated with various enzymes etc. to affect the optical properties in a beneficial way. The fluence rate exiting the cuvette is well described by the familiar Beer's law if scattering and specular reflection are negligible:

$$
\Phi(\mathrm{z})=\Phi(0) \mathrm{e}^{-\mu_{\mathrm{a}} \mathrm{z}}
$$

where: propagation is in the z-direction, fluence rate is measured for some finite thickness $\mathrm{z}$, and $\Phi(0)$ is the immediate sub-surface fluence rate. It is tempting to include the scattering effects of tissues by applying an effective "extinction" coefficient, $\mu_{\text {eff }}$, in Beer's law:

$$
\Phi(\mathrm{z})=\Phi(0) \mathrm{e}^{-\mu_{\mathrm{eff}} \mathrm{z}}
$$

where: the effective attenuation coefficient, $\mu_{\text {eff }}^{2}=3 \mu_{\mathrm{a}}\left[\mu_{\mathrm{a}}+\mu_{\mathrm{S}}(1-\mathrm{g})\right]$, comes from a solution to the diffusion approximation, $\mu_{\mathrm{s}}$ describes attenuation due to scattering, and the "anisotropy factor", $\mathrm{g}$, is commonly used to describe the expected cosine of the refraction angle ${ }^{73}$. If the light is completely scattered in the forward (z) direction $g=1$, while if the light is isotropically scattered uniformly in all directions $\mathrm{g}=0$. The formulation of equation (43) can be effective if the directional nature of the scattered light is included. Scattering is primarily a refraction event and the angle of refraction depends on the angle of incidence relative to the orientation of the scattering center. In standard integrating sphere measurements it is not possible to directly measure $\mu_{\mathrm{s}}$. The measurements yield the "reduced scattering" coefficient, $\mu_{\mathrm{s}}$ ', one of the terms in $\mu_{\mathrm{eff}}$ :

$$
\mu_{\mathrm{s}}{ }^{\prime}=\mu_{\mathrm{s}}(1-\mathrm{g})
$$

When scattering is important the total reflectance from a surface consists of specular reflectance from the surface (angle of incidence equals angle of reflection) plus diffuse reflectance - light radiance which propagates into the tissue, undergoes several refraction events and emerges from the surface in random directions. Scattering also extends the lateral propagation of the incident light, and may result in effective radii up to several times that of the incident light beam.

At a wavelength for which scattering is a dominant propagation effect, the fluence rate just below the surface may be as much as two to three times the fluence rate at the surface if scattering were not important for the same surface irradiation. We will see the importance of this effect in section 7.2, where a specimen of aorta was irradiated with an Argon laser at $514 \mathrm{~nm}$, a highly scattered wavelength. Even larger factors can be obtained when hollow organs, such as the bladder or an air- or gas-filled blood vessel, are irradiated due the "integrating sphere" effect. 


\subsection{Optical Properties of Bovine Aorta}

At both infrared and ultraviolet wavelengths light propagation is dominated by absorption effects. At most of the ultraviolet wavelengths the primary absorbing chromophores are apparently cellular organelles, perhaps the mitochondria. Certainly, absorption by cellular water is the dominant mechanism for wavelengths of interest longer than about $1.5 \mu \mathrm{m}$. The water absorption spectrum has a peak at $\lambda=1.9 \mu \mathrm{m}\left(\mu_{\mathrm{a}}=10 \mathrm{~mm}^{-1}\right)$ and another peak just under $3 \mu \mathrm{m}$, at about $\lambda=2.9 \mu \mathrm{m}$ (where $\left.\mu_{\mathrm{a}}=1000 \mathrm{~mm}^{-1}\right)^{73}$. Absorption at longer wavelengths is almost invariably determined by water absorption; and so the water content of the tissue dominates the absorption coefficient.

\begin{tabular}{cccc} 
Wavelength & Laser Type & $\begin{array}{c}\text { Absorption } \\
\mu_{\mathrm{a}}\left(\mathrm{mm}^{-1}\right)\end{array}$ & $\begin{array}{c}\text { Reduced Scattering } \\
\mu_{\mathrm{s}}\left(\mathrm{mm}^{-1}\right)\end{array}$ \\
\hline \hline $400 \mathrm{~nm}$ & Cu Vapor & 0.3 to 0.6 & 3.5 to 9.5 \\
$515 \mathrm{~nm}$ & 0.1 to 0.2 & 3.5 to 7.5 \\
$514 \mathrm{~nm}$ & Argon & 0.1 to 0.2 & 3.5 to 7.0 \\
$632 \mathrm{~nm}$ & He Ne & 0.1 to 0.2 & 3.0 to 5.5 \\
$800 \mathrm{~nm}$ & Diode & 0.08 to 0.15 & 2.5 to 4.2 \\
$1.06 \mu \mathrm{m}$ & Nd:YAG & 0.1 to 0.15 & 2.2 to 4.0 \\
$1.45 \mu \mathrm{m}$ & Absorption peak & 0.8 to 2.2 & 1.5 to 3.5 \\
$2.01 \mu \mathrm{m}$ & Tm:YAG & 5.62 & \\
$2.09 \mu \mathrm{m}$ & Ho:YAG & 2.82 & \\
$2.94 \mu \mathrm{m}$ & Er:YAG & 960 & \\
$10.6 \mu \mathrm{m}$ & CO2 & 67 &
\end{tabular}

Table 8. Optical properties of bovine aorta at selected wavelengths. Data for wavelengths shorter than $2 \mu \mathrm{m}$ are interpolated from figures in Chan et al ${ }^{75}$. These data were collected over pressures from 0 to $200 \mathrm{kPa}$ and the range of values is given at each wavelength. Both optical properties increase with increasing pressure. Longer wavelength absorption values are estimated from laboratory experience and tissue water content.

\section{THERMAL PROPERTIES OF VESSELS}

The thermal properties required to compute the energy balance (equation 23) are the thermal conductivity, the specific heat, and the density. Tissues are in large part made up of water, and the thermal properties differ little from those of water for most tissues. Perhaps the most complete collection of thermal property data is that of Bowman, Cravalho and Woods 76 . Of all the data collected in that paper only a few of the measurements are germane to blood vessels. The most comprehensive collection of blood vessel data is by Valvano and co-workers $77,78,79$.

The density and specific heat always appear as a multiplicative pair. Given $\mathbf{k}$ and $\alpha$ the pc product may quickly be found. The usual format for thermal property data collection is in terms of the thermal conductivity, $\mathrm{k}$, and the thermal diffusivity, $\alpha$ :

$$
\alpha\left(\frac{\mathrm{cm}^{2}}{\mathrm{~s}}\right)=\frac{\mathrm{k}}{\rho \mathrm{c}}
$$


Several empirical relationships are of use in estimating thermal properties in the absence of data. Spells ${ }^{80}$ determined in biological solutions that:

$$
k=0.54+5.73 \mathrm{~m}_{\mathrm{w}} * \quad \text { for } \mathrm{m}_{\mathrm{w}} *>0.2
$$

where: $\mathrm{k}$ is in $\left(\mathrm{mW} / \mathrm{cm}-{ }^{\circ} \mathrm{C}\right)$, and $\mathrm{m}_{\mathrm{w}}{ }^{*}=$ the mass fraction of water. Cooper and Trezek ${ }^{81}$ found an analogous relationship for tissues:

$$
\mathrm{k}=\rho\left(6.28 \mathrm{~m}_{\mathrm{w}}{ }^{*}+1.17 \mathrm{~m}_{\mathrm{p}}{ }^{*}+2.31 \mathrm{~m}_{\mathrm{f}}^{*}\right)
$$

where: $k$ is again in $\left(\mathrm{mW} / \mathrm{cm}^{\circ}{ }^{\circ} \mathrm{C}\right), \rho$ is the density $\left(\mathrm{g} / \mathrm{cm}^{3}\right), \mathrm{m}_{\mathrm{p}}$ is the mass fraction of protein, and $m_{f} *$ is the mass fraction of fat and the coefficients have the required units. They report similar correlations for specific heat $\left(\mathrm{J} / \mathrm{g}-{ }^{\circ} \mathrm{C}\right)$ and density $\left(\mathrm{g} / \mathrm{cm}^{3}\right)$ :

$$
\begin{gathered}
c=4.2 \mathrm{~m}_{\mathrm{w}}^{*}+1.09 \mathrm{~m}_{\mathrm{p}}^{*}+2.3 \mathrm{~m}_{\mathrm{f}}^{*} \\
\rho=\frac{1}{\mathrm{~m}_{\mathrm{w}}^{*}+0.649 \mathrm{~m}_{\mathrm{p}}^{*}+1.227 \mathrm{~m}_{\mathrm{f}}^{*}}
\end{gathered}
$$

\begin{tabular}{cccc} 
Tissue & Ref. & $\mathrm{k}\left(\mathrm{mW} / \mathrm{cm}-{ }^{\circ} \mathrm{C}\right)$ & $\alpha \times 10^{3}\left(\mathrm{~cm}^{2} / \mathrm{s}\right)$ \\
\hline \hline Normal aorta & 77 & $4.76(0.41)$ & $1.27(0.07)$ \\
Fatty plaque & 77 & $4.84(0.44)$ & $1.28(0.05)$ \\
Fibrous plaque & 77 & $4.85(0.22)$ & $1.29(0.03)$ \\
Calcified plaque & 77 & $5.02(0.59)$ & $1.32(0.07)$ \\
Dog Fem. A. & 77 & 3.91 & \\
Dog Car. A. & 77 & 4.48 & \\
Bovine Aorta, Axial & 78 & $4.91(0.59)$ & \\
Bovine Aorta, Radial & 78 & $3.91(0.13)$ & \\
Muscle & 76 & 2.8 to 5.3 & \\
Fat & 76 & 1.3 to 3.7 & \\
Bone (in vivo) & 76 & 8 to 30 & \\
Plasma & 79 & $5.70(0.10)$ & \\
Whole Blood & 79 & $4.92(0.09)$ & \\
Water & 76 & 5.91 to 6.66 &
\end{tabular}

Table 9. Thermal properties of vessels and related tissues near body temperature. Numbers in parentheses are standard deviations.

Correlations for elevated temperatures are also reported by Valvano et al ${ }^{77}$. For canine femoral artery:

$$
\begin{gathered}
\mathrm{k}=3.688+6.201 \times 10^{-3} \mathrm{~T}\left({ }^{\circ} \mathrm{C}\right) \\
\alpha=1.003 \times 10^{-3}+1.318 \times 10^{-6} \mathrm{~T}\left({ }^{\circ} \mathrm{C}\right)
\end{gathered}
$$

and for canine carotid artery:

$$
\mathrm{k}=4.48+1.64 \times 10^{-5} \mathrm{~T}\left({ }^{\circ} \mathrm{C}\right)
$$




$$
\alpha=1.159 \times 10^{-3}+3.896 \times 10^{-6} \mathrm{~T}\left({ }^{\circ} \mathrm{C}\right)
$$

where: $\mathrm{k}$ is in $\left(\mathrm{mW} / \mathrm{cm}^{\circ}{ }^{\circ} \mathrm{C}\right)$, and $\alpha$ is in $\left(\mathrm{cm}^{2} / \mathrm{s}\right)$.

\section{RADIO FREQUENCY HEATING EFFECTS}

Since the early 1930's electrosurgical current at radio frequencies (RF) between about 500 $\mathrm{kHz}$ and $5 \mathrm{MHz}$ has been used to cut fuse, seal or coagulate resected and transected blood vessels. Sealing and fusion of vessels by electrosurgical current are strongly influenced by the inhomogeneous architecture of the tissue constituents, particularly in the large arteries. Inhomogeneities in electrical properties of the constituents, smooth muscle, collagen and elastin, lead to sharp spatial gradients in volumetric power deposition which result in uneven heating. The mechanical properties of the various tissue constituents are also of considerable importance. Collagen alteration is apparently an important prerequisite to successful tissue fusion $84,85,86,87,88$. Electron microscopic (EM) studies suggest that the fusion process in blood vessels may be dominated by random reentwinement of thermally dissociated adventitial collagen fibrils (Type I) during the end stage heating and early cooling phases 87 .

\subsection{Bipolar Electrode Fields}

The model space consists of the first quadrant (I) of the symmetrical system composed of two bipolar flat plate electrodes clamped transversely around a vessel of arbitrary thickness and composition, as shown in Figure 20. The electrodes are of arbitrary size and potential and an insulated thermocouple (t/c) of arbitrary size can be included. Electrical boundary conditions are: 1) zero flux at $\mathrm{x}=0,2$ ) $\mathrm{V}=0$ at $\mathrm{y}=0$, 3) constant potential under the electrode and zero flux outside the electrode at $y=$ maximum, and 4) either a mixed boundary condition (simulating leakage flux) or a zero flux boundary at $\mathrm{x}=$ maximum. The model space used in the model was $81 \mathrm{H} \mathrm{X} 21 \mathrm{~V}$ nodes capable of 9 tissue layers. The tissue layers may have arbitrary thickness and electrical conductivity and can be represented by a selectable number of node spaces. Interfaces between tissues are constrained to lie along node planes. Calculations of electrode current and power are on a per unit length basis along the Z-axis.

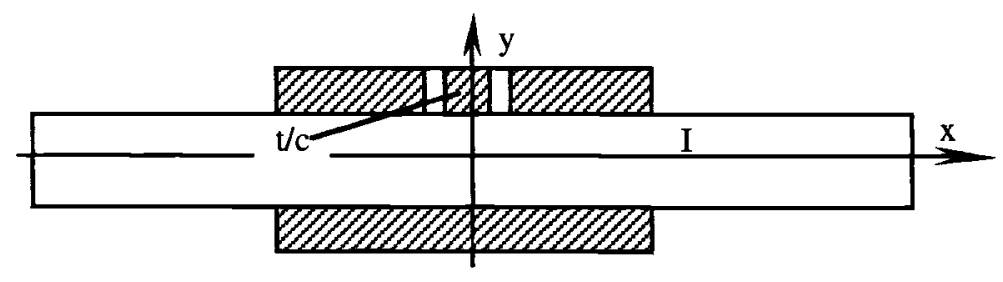

Figure 20. Idealized Cartesian 2-D model space of the first quadrant of bipolar electrodes (cross-hatched) clamped symmetrically around a vessel. Thermocouple $(\mathrm{t} / \mathrm{c})$ may be included.

The electrical conductivities used in the calculations were: 1 ) for collagen, $\sigma_{\mathrm{c}}=0.26 \mathrm{~S} / \mathrm{m}$ (transverse), 2) for elastin, $\sigma_{\mathrm{e}}=0.67 \mathrm{~S} / \mathrm{m}$ (transverse), 3) for smooth muscle no published values are available - an estimate was formed using published values for cardiac muscle (values range from 0.11 to $0.47 \mathrm{~S} / \mathrm{m}^{72}$ ) the geometric mean of $\sigma_{\mathrm{m}}=0.23$ 
$\mathrm{S} / \mathrm{m}$ was used for these calculations. Transverse conductivities were chosen because the primary electric field direction was transverse to the fibers and plates. Cardiac muscle was thought to be a more effective electrical analog of smooth muscle than skeletal muscle since it is essentially devoid of the cascade of collagenous connective tissue shrouds which electrically and mechanically isolate the skeletal muscle fibers. Both models have an "intima" $10 \mu \mathrm{m}$ thick (actual dimensions in vessels are closer to 1 to $3 \mu \mathrm{m}$ ) modeled by muscle properties and an "internal elastic lamina" $20 \mu \mathrm{m}$ thick (close to the actual dimension) for which elastin properties were used. For both models the electrode was 0.5 $\mathrm{mm}$ thick and $4 \mathrm{~mm}$ across (assigned nodes 1 to 41 ) with no specific thermocouple site. The major difference between the models is the location of the elastin plates: in the media for the carotid artery and in the adventitia for the femoral artery.

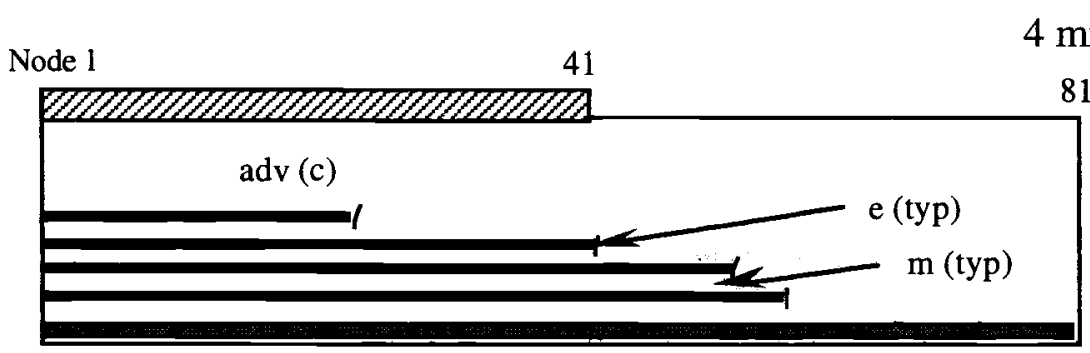

(a)

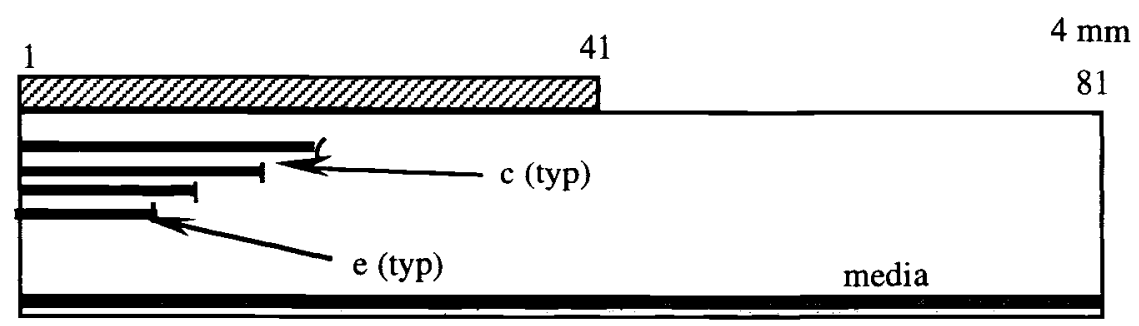

(b)

Figure 21. Vessel model dimensions in the $81 \times 21$ model space for a) canine carotid artery and b) canine femoral artery. Tissue constituents are collagen (c), elastin (e) and smooth muscle (m). Both models have an intima $10 \mu \mathrm{m}$ thick (bottom) and an internal elastic lamina $20 \mu \mathrm{m}$ thick just above it (dark shade). Specific dimensions are in the text.

\subsubsection{Canine carotid artery model.}

Specific dimensions in the carotid artery model are: 1) $0.38 \mathrm{~mm}$ thick overall with 2) an adventitia (collagen mat) $0.17 \mathrm{~mm}$ thick, assigned 4 node spaces, 2) four pairs of elastin/muscle layers, each elastin layer $10 \mu \mathrm{m}$ thick and each muscle layer $50 \mu \mathrm{m}$ thick, assigned 2 node spaces for each layer. The potential field is shown in figure 22a while the volumetric power density $\left(\mathrm{W} / \mathrm{mm}^{3}\right)$ is in figure $22 \mathrm{~b}$. The maximum of the power density was to $27 \mathrm{~W} / \mathrm{mm}^{3}$, and the gray scale covers 0 to $10 \mathrm{~W} / \mathrm{mm}^{3}$. The electrical model converged to a maximum electrode current change of $0.001 \%$ in 10 iterations after 3460 iterations. For a single electrode potential of 50 volts $\left(100 \mathrm{~V}_{\mathrm{rms}}\right.$ bipolar $)$ the current per unit length was $84.4 \mathrm{~mA} / \mathrm{mm}$ and resistance per unit length was $592 \Omega / \mathrm{mm}$. For 7 $\mathrm{mm}$ of vessel in contact with the electrode, this would correspond to a total current of 591 
$\mathrm{mA}$ and inter-electrode resistance of $85 \Omega$, both reasonable values in the light of experimental results.

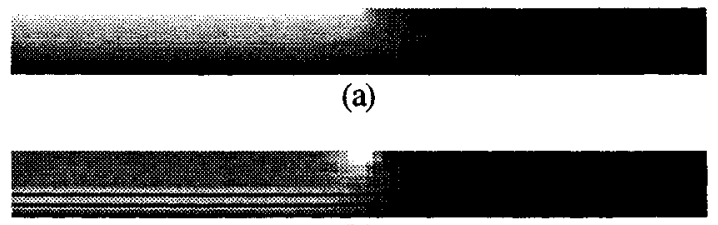

(b)

Figure 22. Geometrically scaled carotid artery E-field model results. (a) Potential field (0 black to $50 \mathrm{~V}$ white, interpolated). (b) power density ( 0 black to $10 \mathrm{~W} / \mathrm{mm} 3$, white, no interpolation used).

The voltage gradient is very strong at the edge of the electrode, as expected, with a correspondingly high power density there. The high edge power density is moderated by strong heat transfer effects in the thermal model, figure 23. The variation in electrical properties of the elastin and muscle in the media is plainly visible in the power density field. The heating time was $4 \mathrm{~s}$. (current adjusted to $42.2 \mathrm{~mA} / \mathrm{mm}$ ) with a $1 \mathrm{~s}$ cooling period, Figures 12 and 13, and required 9 hours to calculate (for the same time step). Tissue thermal properties were assumed similar to those of water and the vessel is assumed thermally linear homogeneous and isotropic. Water vaporization (i.e. boiling) was assumed to occur at rates low enough that no significant tissue pressure increases resulted. Consequently, all vaporization processes occurred at or below $100^{\circ} \mathrm{C}$; all qgen in excess of that required to supply local heat transfer processes was assumed to apply to local equilibrium boiling at $100^{\circ} \mathrm{C}$. Tissue was allowed to increase in temperature above $100^{\circ} \mathrm{C}$ only if fully desiccated.

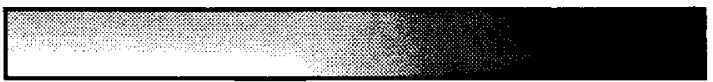

(a)

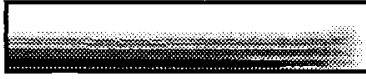

(b)

Figure 23. Geometrically scaled results for the carotid artery model at $4 \mathrm{~s}$. a) Temperature field $\left(0{ }^{\circ} \mathrm{C}\right.$ black to $100{ }^{\circ} \mathrm{C}$ white, interpolated). b) remaining tissue water distribution (range $0 \%$, black, to $55 \%$, white, by volume).

The thermal conductivity turns out to be a particularly strong influence on the results in the vertical direction since the vessels are very thin and the thermal mass of the electrode is significant. Thermal conduction in the horizontal direction is negligible. Tissue density is very close to that of water and was assumed constant.

\subsubsection{Canine femoral artery model.}

Specific dimensions for the femoral model artery are: 1) $0.46 \mathrm{~mm}$ thick overall with 2) an adventitia composed of four pairs of elastin/collagen layers, each elastin layer $10 \mu \mathrm{m}$ thick and each collagen layer $50 \mu \mathrm{m}$ thick (except for the upper-most collagen layer which was $80 \mathrm{~mm}$ thick), assigned 2 node spaces for each layer, and 3) the media (muscle) 0.22 
mm thick, assigned 4 node spaces. The electrical model converged to a maximum electrode current change of $0.001 \%$ in 10 iterations after 1660 iterations. For a single electrode potential of 50 volts $(100 \mathrm{v}$ bipolar) the current per unit length was 62.1 $\mathrm{mA} / \mathrm{mm}$ and resistance per unit length was $805 \Omega / \mathrm{mm}$, higher than the carotid artery model. For $7 \mathrm{~mm}$ of vessel in contact with the electrode, this would correspond to a total current of $435 \mathrm{~mA}$ and inter-electrode resistance of $115 \Omega$, both reasonable values in the light of experimental results, and following the trend observed in the experiments.

The potential field is shown in Figure 24a while the volumetric power density $\left(\mathrm{W} / \mathrm{mm}^{3}\right.$ ) is in Figure 24b. The maximum of the power density was to $15.6 \mathrm{~W} / \mathrm{mm}^{3}$, and the gray scale covers 0 to $10 \mathrm{~W} / \mathrm{mm}^{3}$. Both the potential and power density fields have a markedly different appearance than for the carotid artery model.

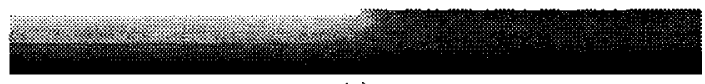

(a)

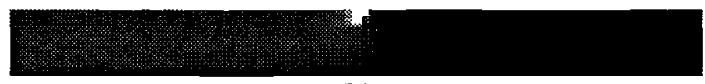

(b)

Figure 24. Geometrically scaled femoral artery E-field model results. a) Potential field (0 black to $50 \mathrm{~V}$, white interpolated) and b) power density ( 0 black to 10 white $\mathrm{W} / \mathrm{mm}^{3}$, no interpolation used).

Again, the voltage gradient is very strong at the edge of the electrode with a correspondingly high power density located there. The variation in electrical properties of the elastin and collagen in the adventitia is not visible in the power density field, however, unlike the carotid artery results.

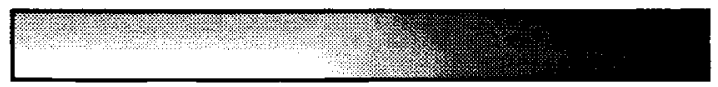

(a)

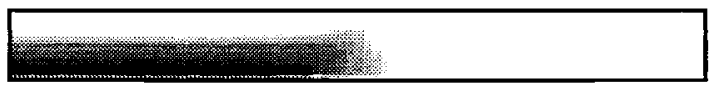

(b)

Figure 25. Geometrically scaled results for the femoral artery model. (a) Temperature field (0 to $100^{\circ} \mathrm{C}$, interpolated). (b) remaining tissue water distribution (range $0 \%$, black, to $55 \%$, white, by volume).

\subsubsection{Fusion seals in larger arteries}

Sealing processes in larger arteries are complicated by the vessel mechanics. Heat damaged collagen and elastin shrink in length and swell in thickness. As in laser anastomosis, tissue fusion attains a primary bond by heating collagenous structures to temperatures sufficient to unravel the fibrous array. The fibers re-entwine at lower temperatures during the cooling phase. Re-entwinement is random and either of low probability or of fundamentally differing bond type since the fused tissue is of low tensile strength compared to undamaged tissue in situ. The temperature history must not create 
brittle collagen at the interface by excessive desiccation in order for the fusion process to be successful.

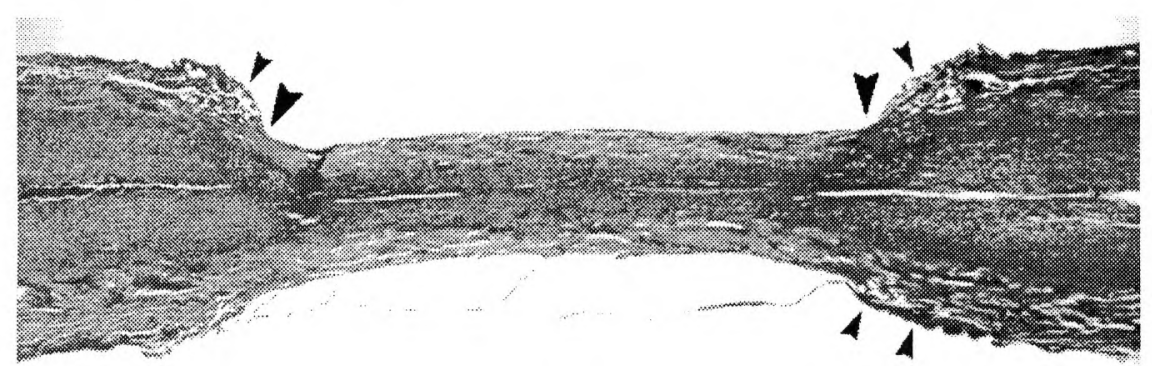

(a)

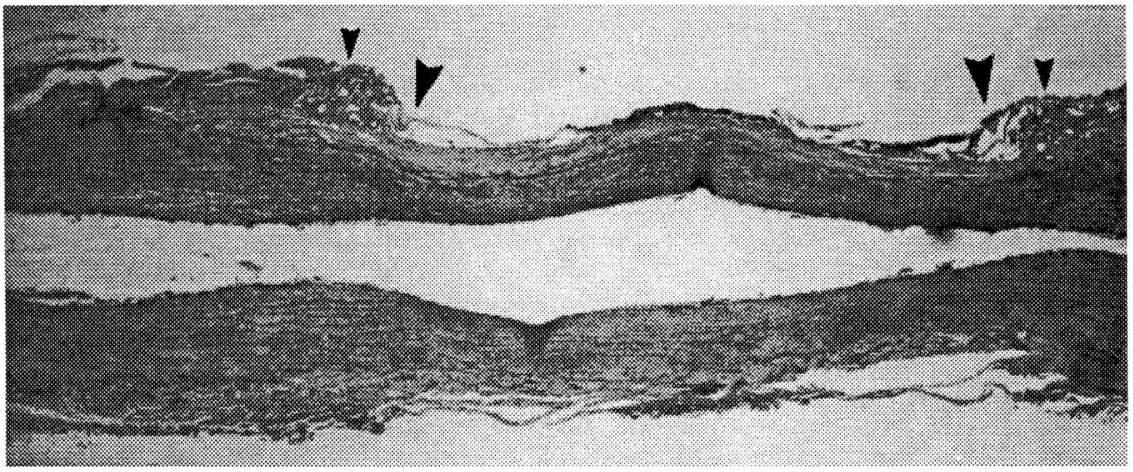

(b)

Figure 26. Radio frequency current sealing in carotid artery in the dog at $20 \mathrm{X}$ original magnification. Large arrows indicate edges of bipolar electrodes, small arrows indicate steam vacuoles. a) successful seal, H\&E stain. b) failed seal, elastin stain.

\subsection{Vaporization in the Aorta}

The effect of water vaporization in highly compartmentalized vessels like the aorta is to create a field of steam vacuoles. Figure 27 is the result of an approximately uniform electric field with current density high enough to cause severe boiling in a post mortem sample of human aorta. The pockets created by the elastin plates of the media confine evolved water vapor and result in the steam vacuoles in the figure. The volume power generation term was larger in the elastin rich media than in the surrounding muscular media owing to differences in the effective electrical conductivity. 


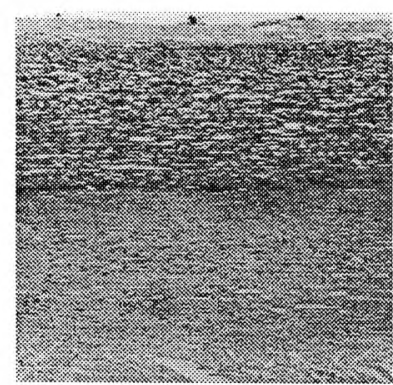

(a)

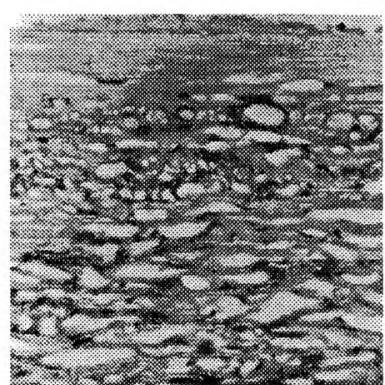

(b)

Figure 27. Human aorta damaged by uniform current density sufficient to reach boiling temperatures. Intimal surface is at the top. (a) At original magnification $100 \mathrm{X}$ the vacuoles are confined to the elastin-rich media where the plates have confined the vapor resulting in severe vacuolization at high boiling rates. (b) At original magnification of $400 \mathrm{X}$ the location of the vacuoles between elastin plates may be seen. [Mallory's trichrome stain]

\subsection{Mesenteric Artery-Vein Coagulation}

Sealing of a large tissue bundle, such as the mesenteric artery-vein pair shown in figure 28 , is not always successful. In the figure, the tissue was damaged to coagulation levels at the edges of the bipolar electrodes but not across the cross-section, so no seal was obtained. High electrode pressure and temperatures often in excess of $100^{\circ} \mathrm{C}$ are required to establish a reliable seal.

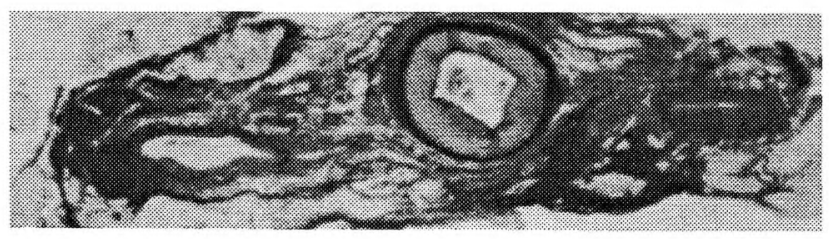

Figure 28 Mesenteric artery-vein pair in the pig after heating with RF current from bipolar electrodes. Current concentrations at the electrode edges have damaged the collagen connective tissue (darkened masses) but no seal was accomplished in any of the vessels. Weigert-vanGieson elastin stain.

\section{LASER HEATING EFFECTS}

\subsection{Laser Vascular Anastomosis.}

Electron microscopic (EM) studies suggest that the fusion process in blood vessels may be dominated by random re-entwinement of thermally dissociated adventitial collagen fibrils (Type I) during the end stage heating and early cooling phases 91 . At the light microscopic level, this bonding process is reflected by the formation of an amorphous coagulum of thermally coagulated adventitial collagen at the anastomotic site. 


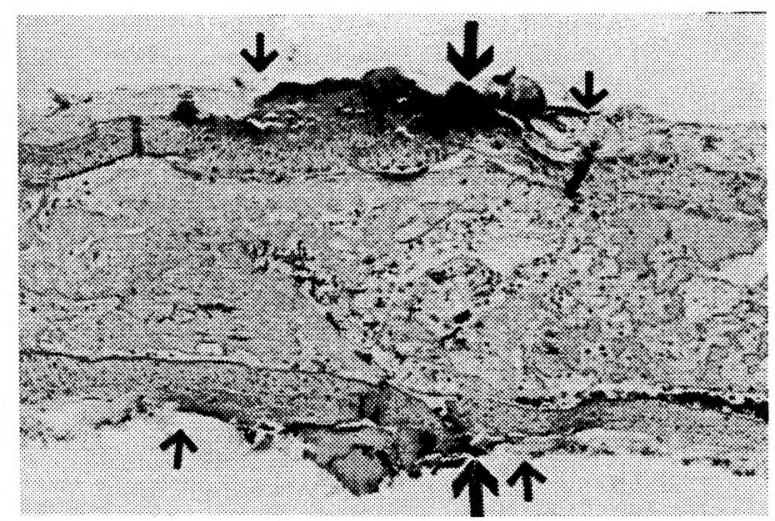

(a)

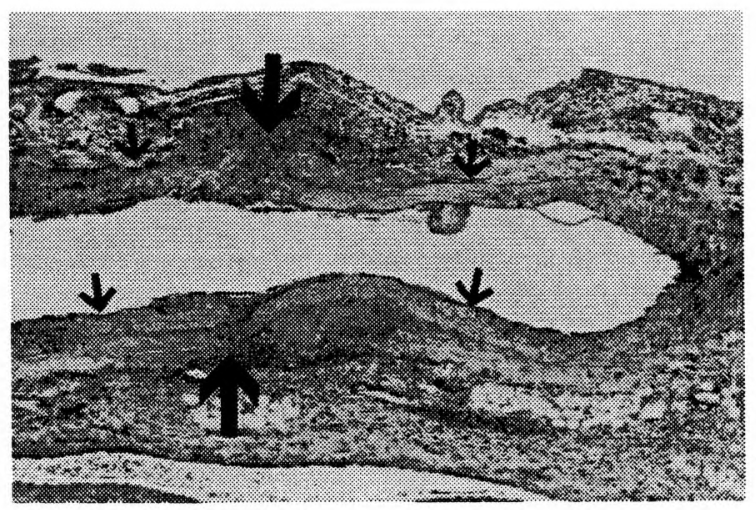

(b)

Figure 29: Longitudinally oriented light microscopic sections of rat femoral artery anastomoses obtained with a $\mathrm{CO}_{2}$ laser beam..$^{90}$ a) Five minutes after anastomosis. The bond is formed by a glassy coagulum (small arrows) of adventitial collagen that is not carbonized but stains darkly with the eosin dye thus obscuring the fused cut ends (large arrow) of the vessels. The average radius of collagen hyalinization in this section is $0.22 \mathrm{~mm}$. (hematoxylin and eosin -- original magnification 160X). b) Three days after anastomosis. Thermally induced smooth muscle necrosis is detectable at three days (small arrows). The radius of total smooth muscle necrosis (die back) in this specimen is $0.58 \mathrm{~mm}$. The severed ends of the artery are embedded in fibrin, which usually fills the anastomotic site at this time (large arrows). (hematoxylin and eosin stain -- original magnification $80 \mathrm{X}$ ). This figure is from reference ${ }^{90}$, used with permission.

The temperature history must not create brittle collagen at the interface by excessive desiccation 92 in order for the fusion process to be successful. Feedback control of tissue fusion by measurements of tissue surface apparent temperature using, for example, thermal infra-red (IR) sensors may require differing temperature history algorithms to obtain comparable welds depending on the dimensional and structural characteristics of the tissue and on the laser wavelength used. Tissue water is the dominant thermodynamically 
active material and, for the $\mathrm{CO}_{2}$, Th:YAG, Er:YAG and $\mathrm{Ho}$ :YAG lasers, the dominant chromophore, as well.

Histologically, the anastomotic site in arteries collected within 5 minutes of the completion of the anastomosis is marked by the formation of a densely staining, glassy (hyalinized) coagulum of thermally altered adventitial collagen which forms the blood tight bond (figure 29a). However, the full extent of lethal cellular thermal damage cannot be determined until about 3 days later when the heat-killed smooth muscle cells of the medial portion of the arterial wall have undergone necrosis (Figure 29b).

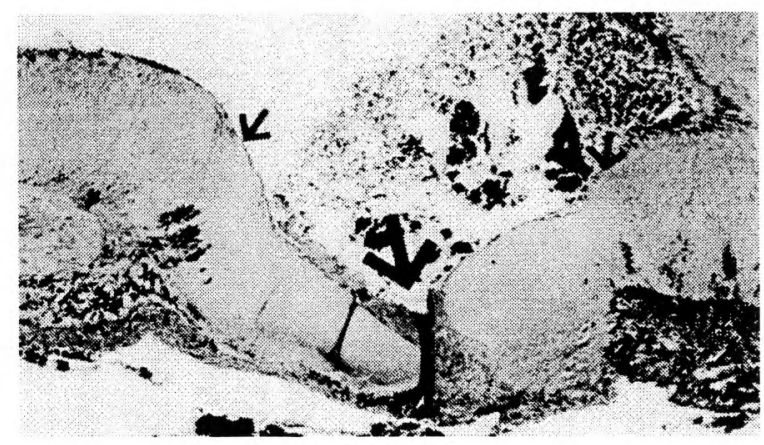

Figure 30: Longitudinally oriented light microscopic sections of dog brachial artery laser anastomosis harvested one week after the bonding procedure ${ }^{90}$. The boundaries of smooth muscle necrosis (small arrows) are distinct. A fold in the tissue section partially obscures the anastomotic site (large arrow). (Hematoxylin and eosin stain -- original magnification $50 \mathrm{X}$ ). This figure is from reference ${ }^{90}$, used with permission.

\subsection{Argon Laser Heating in Aorta}

The effects of high local tissue pressures have been observed in many studies when, for example, highly scattered argon laser irradiation is used to ablate vessel wall. The scattering events result in high fluence rates just below the tissue surface and corresponding thermally induced stresses. An example of water vapor dominated tearing is shown in figure 31. A post mortem sample of human aorta was irradiated with an Argon laser at $514 \mathrm{~nm}$. An ablation crater was created in the surface by explosive vaporization, as well as a sub-surface dissection in a region of high local fluence rate. The scattering resulted in higher fluence rates below the surface and high pressure from confined steam evolution created the dissection approximately along an elastin plate boundary. The laser beam power was $2.5 \mathrm{~W}$., beam radius $1 \mathrm{~mm}$, duration $2.5 \mathrm{~s}$ and the maximum surface center temperature recorded by thermographic imaging at video rates was $175^{\circ} \mathrm{C}$ immediately prior to explosive vaporization. 


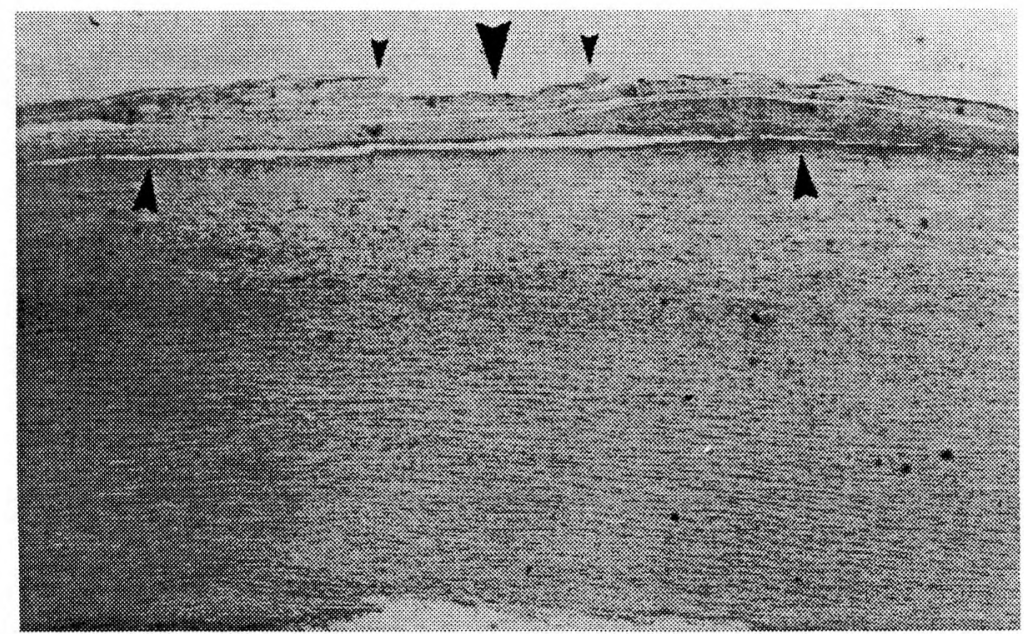

Figure 31: Argon laser irradiation of aorta at $40 \mathrm{X}$ original magnification, H\&E stain. The largest arrow indicates the approximate center of the $2 \mathrm{~mm}$ diameter laser beam. The smallest arrows indicate the approximate edge of the ablation crater (some intimal tissue is missing on the right side of the crater) and the middle sized arrows indicate a sub-surface dissection created by steam generation from high local fluence rates due to scattering processes.

\section{ACKNOWLEDGMENTS}

The authors would like to express their appreciation to the Texas Higher Education Coordinating Board (grant number ARP-138), to Valleylab Inc., to the Whitaker Foundation, to the National Science Foundation (grant number BCS-8451123) and to the Air Force Office of Scientific Research through MURI from DDR\&E (F49620-98-10480) for partial support of this work.

\section{REFERENCES}

1. Bloom and D.W. Fawcett, Textbook of Histology, 12th Ed. Chapman and Hall, New York, 1993.

2. A. P. Spence, Basic Human Anatomy $2^{\text {nd }}$ Ed., Benjamin Cummings, Menlo Park CA, 1986.

3. L.C. Junqueira, J. Carneiro, A. Contopoulos, Basic Histology, Lance, Los Altos, CA, 1975.

4. W.D. Gardner and W. A. Osburn, Structure of the Human Body, W.B. Saunders, Philadelphia, 1973.

5. P.S. Amenta, Elias-Pauly's Histology and Human Microanatomy, John Wiley \& Sons, New York, 1987.

6. M.D.S. Frame, "Shear rate gradient in arteriolar bifurcations: theoretical and experimental", Proc. IEEE $21^{\text {st }}$ Ann. Conf. on Engr. in Med. \& Biol. Soc., paper no. 2.3.7-2, (proc. on CD-ROM) 1999.

7. M.E. Nimmi (Ed); Collagen; Volume I, Biochemistry, CRC Press, Boca Raton, FL, 1988. 
Matching the Energy Source to the Clinical Need / 273

8. G. Hagen, "Uber die Bewegung des Wassers in engen zylindrischen Rohren", Pogg. Ann. 46, 423-442, 1839. As described in ${ }^{17}$.

9. J. Poiseuille, "Récherches expérimentelles sur le mouvement des liquides dans les tubes de trés petits diamétres", Compte Rendus, 11, 961-967 and 1041 - 1048 (1840). As described in 17 .

10. A.C. Burton, Physiology and Biophysics of the Circulation,

11. C.G. Caro, T.J. Pedley, R.C. Schroter and W.A. Seed The Mechanics of the Circulation, Oxford University Press, New York, 1978.

12. Y. Qiu and J.M. Tarbell, "Phase angle between circumferential strain and wall shear stresses affects endothelial cell biochemical production", Proc. IEEE $21^{\text {st }}$ Ann. Conf. on Engr. in Med. \& Biol. Soc., paper no. 2.3.7-3, (proc. on CDROM), 1999.

13. D.R. Karolyi, S. Jin, L. Knoepp, C.M. Brophy, D.P. Giddens, "The effect of aortic coarctation on shear stresses and flow fields through the rabbit aortic bifurcation", Proc. IEEE $21^{\text {st }}$ Ann. Conf. on Engr. in Med. \& Biol. Soc., paper no. 2.3.7-6, (proc. on CD-ROM) 1999.

14. S.L. Soo, Fluid Dynamics of Multiphase Systems, Ginn-Blaisdell, Walthham, MA, 1967.

15. A. Noordergraaf, Circulatory System Dynamics, Academic Press, New York, 1978.

16. O. Reynolds, "An experimental investigation of the circumstances which determine whether the motion of water shall be direct or sinuous, and of the law of resistance in parallel channels", Phil. Trans. Royal Soc., London, 174, 935-982, 1883. As described in ${ }^{17}$.

17. H. Schlicting, Boundary Layer Theory, $6^{\text {th }}$ Ed., McGraw-Hill, New York, 1968.

18. M.L. Rhagavan D.A Vorp, M.P. Federle, M.S. Makaroun, M.W. Webster, "Mechanical stresses on three-dimensionally reconstructed models of abdominal aortic aneurysm", Proc. IEEE $21^{\text {st }}$ Ann. Conf. on Engr. in Med. \& Biol. Soc., paper no. 2.3.7-4, (proc. on CD-ROM) 1999.

19. J. Humphey, "Mechanics of the arterial wall: review and directions", Critical Reviews in Biomedical Engineering (Begell House Publishing), 23, 1-162 (nos. 1 and 2, complete), 1995.

20. T.R. Canfield and P.B. Dobrin, "Static elastic properties of blood vessels", in Handbook of Bioengineering, R. Salak and S. Chien Eds., McGraw-Hill, New York, 1987.

21. F.H. Silver, D.L. Christiansen and C.M. Buntin, "Mechanical properties of the aorta: a review" CRC Crit. Rev. Biomed. Engr. 17, 323-358, 1989.

22. Y.C. Fung, S.Q. Liu and J.B. Zhou, "Remodeling of the constitutive relation while a blood vessel remodels itself", Trans. ASME J. Biomech. Engr., 115, 453459, 1993.

23. J.G. Myers, J.A. Moore, M. Ojha, K.W. Johnston, C.R. Ethier, "Waveform dependence of wall shear stresses in a human right coronary artery", Proc. IEEE $21^{\text {st }}$ Ann. Conf. on Engr. in Med. \& Biol. Soc., paper no. 2.3.7-1, (proc. on CDROM) 1999.

24. R.T. Lee and R.D. Kamm, "Vascular mechanics for the cardiologist", Am. J. Cardiol., 23, 1289-1295, 1994.

25. J.M. Clark and S. Glagov, "Transmural organization of the arterial media" Arteriosclerosis, 5, 19-34, 1985.

26. S.Q. Liu and Y.C. Fung "Zero stress states of arteries", Trans. ASME J. Biomech. Engr., 110, 82-84, 1988. 
27. Y.C. Fung and S.Q. Liu, "Change of residual strains in arteries due to hypertrophy caused by aortic constriction", Circ. Res. 65, 1340-1349, 1989.

28. S.Q. Liu and Y.C. Fung "Relationship between hypertension, hypertrophy and opening angle of zero-stress state of arteries following aortic constriction", Trans. ASME J. Biomech. Engr., 111, 325-335, 1989.

29. H.C. Han and Y.C. Fung "Species dependence of the zero-stress state of the aorta: pig versus rat", Trans. ASME J. Biomech. Engr., 113, 446-451, 1991.

30. J. Vossoughi, Z. Hedjazi and F.S. Borris, "Intimal residual stress and strain in large arteries", In 1993 Advances in Bioengineering, New York, 1993.

31. T.J. Van Dyke and A. Hoger, "Growth-induced residual stresses and opening angles in soft biological tissues", Proc. 36th Ann. Meeting, Soc. of Engr. Sciences, paper no. MA7-2, 1999.

32. R.H. Cox, "Comparison of carotid artery mechanics in the rat, rabbit and dog", Am. J. Physiol., 234, H280-288, 1978.

33. R.H. Cox, "Regional variation of series elasticity in canine arterial smooth muscle", Am. J. Physiol., 234, H542-551, 1978.

34. R.H. Cox, "Passive mechanics and connective tissue composition of canine arteries", Am. J. Physiol., 234, H533-541, 1978.

35. R.H. Cox, "Differences in mechanics of arterial smooth muscle from hind limb arteries", Am. J. Physiol., 234, H649-656, 1978.

36. F.P. Incropera and D.P. DeWitt, Fundamentals of Heat and Mass Transfer, 4th Ed., John Wiley \& Sons, New York, 1996.

37. W.M. Rosenhow and H.Y. Choi, Heat, Mass and Momentum Transfer, PrenticeHall, Englewood Cliffs, NJ, 1961.

38. F. Kreith and M.S. Bohn, Principles of Heat Transfer, West Publ., St. Paul, MN, 1993.

39. W.M. Kays and M.E. Crawford, Convective Heat and Mass Transfer, McGrawHill, New York, 1980.

40. A. Shitzer and R.C. Eberhart, Heat Transfer in Medicine and Biology, Plenum Press, New York, 1985.

41. R. Siegel and J.R. Howell, Thermal Radiation Heat Transfer, 3rd Ed., Taylor \& Francis, Washington, DC, 1992.

42. J.C. Chato, "Heat transfer to blood vessels", Trans. of the ASME, J. of Biomech. Engr., 102, 110-118, 1980.

43. M.M. Chen and K.R. Holmes, "Microvasculature contributions in tissue heat transfer, In Thermal Characteristics of Tumors: Applications in Detection and Treatment, R.K.Jain and P.M. Gullino Eds. Ann. N.Y. Acad. of Sci., 335, 137$150,1980$.

44. M.M. Chen, "The tissue energy balance equation", Chapter 7 in Heat Transfer in Medicine and Biology, Shitzer and Eberhart, Eds., Plenum Press, New York, 1985.

45. H.H. Pennes, "Analysis of tissue and arterial blood temperatures in the resting human forearm", J. Appl. Physiol. 1, 93-122, 1948.

46. E.H. Wissler, "A mathematical model of the human thermal system", Bull. Math. and Biophys., 26, 147-166, 1964.

47. J.A. Stolwijk, "Mathematical model of thermoregulation", In Physiological and Behavioral Temperature Regulation, J.D. Hardy et al Eds., pp703-721, Thomas, Springfield IL, 1971.

48. W.J. Song, S. Weinbaum and L.M. Jiji, "A theoretical model for peripheral tissue heat transfer using the bioheat equation of Weinbaum and Jiji", Trans. of ASME, J. of Biomech. Engr., 109, 72-78, 1987. 
49. C.K. Charny, S. Weinbaum and R.L. Levin, "An evaluation of the WeinbaumJiji bioheat equatin for normal and hyperthermic conditions", Trans. of ASME, J. of Biomech. Engr., 112(1), 80-87, 1990.

50. A.R. Moritz and F.C. Henriques, "Studies in thermal injury: II the relative importance of time and surface temperature in the causation of cutaneous burns" Am. J. Pathol. 23(5), 695-720, 1947.

51. J.A. Pearce, S. Thomsen, H. Vijverberg and T.J. McMurray, "Kinetics for birefringence changes in thermally coagulated rat skin collagen", Proc. SPIE 1876, 180-186, 1993.

52. S. Thomsen, J.A. Pearce and W. F. Cheong, "Loss of birefringence as a low temperature marker of thermal damage in tissues", IEEE Transactions on Biomedical Engineering BME-36 (12), 1174-1179, 1989.

53. K.R. Diller, J.W. Valvano and J.A. Pearce, Bioheat Transfer, Section 4 of Chapter 4 "Applications" in Handbook of Thermal Engineering, F. Kreith, Ed., CRC Press (in press).

54. A.N. Takata et al, "Thermal model of laser induced eye damage", Final Report USAF School of Aerospace Med., Brooks AFB, TX, Contract F41609-74-C-0005, IIT Research Institute, Chicago, IL, 1974.

55. A.J. Welch, G.D. Polhamus, "Measurement and prediction of thermal injury in the retina of the Rhesus monkey", IEEE Trans. Biomed. Engr. BME-31, 633-644, 1984.

56. R. Birngruber, F. Hillenkamp, V-P. Gabel, "Theoretical investigations of laser thermal retinal injury", Health Phys., 48, 781-796, 1985.

57. F.C. Henriques, "Studies of thermal injury V: The predictability and significance of thermally induced rate processes leading to irreversible injury", Arch. Pathol. 43, 489-502, 1947.

58. J.A. Weaver and A.M. Stoll, "Mathematical model of skin exposed to thermal radiation", Aerospace Med., 40 (1), 24, 1969.

59. Y. Yang, A.J. Welch and H.G. Rylander III, "Rate process parameters of albumen", Lasers in Surg. \& Med., 11, 188-190, 1991.

60. R. Agah, "Quantitative characterization of arterial tissue thermal damage", MSE thesis, The University of Texas at Austin, 1988.

61. J.A. Pearce, S. Thomsen, H. Vijverberg and T. J. McMurray, "Kinetics for birefringence changes in thermally coagulated rat skin collagen", Proc. SPIE, 1876, 180-186, 1993.

62. T. Kang, J. Resar, and J.D. Humphrey, "Heat-induced changes in the mechanical behavior of passive coronary arteries", Trans. ASME J. Biomech. Engr., 117, 8693, 1995.

63. J.H Keenan and F.G Keyes, Thermodynamic Properties of Steam 1st Ed., John Wiley, New York, 1948.

64. W. Brutasaert, Evaporation Into the Atmosphere: Theory, History and Applications, D. Reidel, Dordrecht Netherlands, 1982.

65. J.H. Torres, M. Motamedi, J.A. Pearce and A.J. Welch, "Experimental evaluation of mathematical models for predicting the thermal response to laser irradiation", Appl. Optics, 32(4), 597-606, 1993.

66. V.P. Skripov, Metastable Liquids, (translated from Russian by R. Kondor), John Wiley and Sons, New York, 1974.

67. E. Gerum, J. Straub and U. Grigull, "Examination of the metastable state of liquids", Chapter 19 in Heat Transfer in Boiling, E. Hahne and U. Grigull Eds., Academic Press, New York, 1977.

68. D. T. Paris and F.K. Hurd Basic Electromagnetic Theory McGraw-Hill, New York, 1969. 
69. G. Roussy and J.A. Pearce Foundations and Industrial Applications of Microwaves and Radio Frequency Fields: Physical and Chemical Processes; John Wiley \& Sons, Chichester, UK, 1995.

70. J.A. Pearce and S. Thomsen, "The effect of vessel architecture on fusion by radio frequency current, Proc. SPIE, 3249, 217-228, 1998.

71. H.P. Schwann, "Biophysics of Diathermy", Chapter 3 of Therapeutic Heat and Cold, S. Licht Ed.; Waverly Press, Baltimore MD, 1965.

72. L.A. Geddes and L.E. Baker, "The specific resistance of biological material. A compendium of data for the biomedical engineer and physiologist", Med. \& Biol. Engr., 5, 271-293, 1967.

73. A.J. Welch and M.J.C. vanGemert, (Eds.), Optical-Thermal Response of LaserIrradiated Tissue, Plenum, New York, 1995.

74. M.L. Wolbarsht, Laser Applications in Medicine and Biology, Plenum, New York, 1974.

75. E.K. Chan, B. Sorg, D. Protsenko, M. O'Neil, M. Motamedi, and A.J. Welch, "Effects of compression on soft tissue optical properties", IEEE J. Sel. Topics in Quant. Mech., 2(4), 943-950, 1996.

76. H.F. Bowman, E.G. Cravalho and M. Woods, "Theory, measurement and application of thermal properties of biological materials", Ann. Rev. of Biophys \& Bioengr. 4, pp43-80, 1975.

77. J.W. Valvano and C. Chitsabesan, "Thermal conductivity and diffusivity of arterial wall and atherosclerotic plaque", Lasers in the Life Sciences, 1, 219-229, 1987.

78. V.K. Dalvi, "Thermal conductivity measurement of arterial walls", M.S. Thesis, Biomedical Enginering Program, The University of Texas at Austin, 1993.

79. T.A. Balasubramaniam and H.F. Bowman, "Thermal conductivity and thermal diffusivity of biomaterials. A simultaneous measurement technique", J. Biomech. Engr., 99, 148-154, 1977.

80. K.E. Spells, "The thermal conductivities of some biological fluids", Phys. Med. \& Biol., 5, 139-153, 1960.

81. T.E. Cooper and G.J. Trezek, "Correlation of thermal properties of some human tissues with water content", Aerosp. Med., 42, 24-27, 1971.

82. T.A. Magnusen and J.A. Pearce, "Temperature controlled electrosurgical vessel sealing", Proc. IEEE-EMBS 16th Annual Meeting (CD-ROM), 1994.

83. J.S. Kennedy J.A. Pearce and S. Thomsen, "Mechanisms of electrosurgical fusion for large vessel hemostasis, Proc. 7th Intl. Mtng, Soc. Min. Invas. Therapy (in J. Min. Invas. Therap., 4 Suppl 1, p19), 1995.

84. G.M. Lemole, R.R. Anderson and S. DeCoste; "Preliminary evaluation of collagen as a component in the thermally-induced 'weld' " Proc. SPIE 1422:116$122,1991$.

85. R.A. White, G.E. Kopchok and G. White, "Vascular tissue bonding using laser surgery" Lasers in Cardiovascular Medicine and Surgery: Fundamentals and Techniques. G. Abela ed. pp361-372, Kluwer Academic Press. Boston, 1990.

86. G.E. Kopchock, R.A. White, H.J. White et al; " $\mathrm{CO}_{2}$ and argon laser vascular welding: acute histologic an thermodynamic comparison", Lasers in Surgery and Medicine 8(6) 584-588, 1988.

87. R. Schober, F. Ulrich, T. Sander, H. Durselen and S. Hessel; "Laser-induced alteration of collagen substructure allows microsurgical tissue welding" Science 232:1411-1421, 1986.

88. M.R. Treat, C.O. Mehmet, and L.S. Bass, "New technologies and future applications of surgical lasers" Surgical Clinics of North America 72(3), 705-42, 1992. 
89. C.R. Neblett, J.R. Morris and S. Thomsen; "Laser-assisted microsurgical anastomosis" Neurosurgery 19, 914-934, 1986.

90. J.A. Pearce and S. Thomsen, "Kinetic models of tissue fusion processes", Proc. SPIE 1643:251-260, 1992.

91. R. Schrober, F. Ulrich, T. Sander, H. Durselen, and S. Hessel, "Laser-induced alteration of collagen substructure allows microsurgical tissue welding", Science 232, 1411-1421, 1986.

92. M. Quigley, H. Bailes, H. Kwan, L. Cerullo, J.T. Brown; "Aneurysm formation after low power $\mathrm{CO}_{2}$ laser assisted vascular anastomosis" Neurosurgery 18, 292298, 1986. 